\title{
Nanomaterials for Modulating the Aggregation of $\beta$-Amyloid Peptides
}

\author{
Yaliang Huang ${ }^{1,2}$, Yong Chang ${ }^{2}$, Lin Liu ${ }^{2, *}$ and Jianxiu Wang ${ }^{1, *}$ \\ 1 Hunan Provincial Key Laboratory of Micro \& Nano Materials Interface Science, College of Chemistry and \\ Chemical Engineering, Central South University, Changsha 410083, China; 182301010@csu.edu.cn \\ 2 Henan Province of Key Laboratory of New Optoelectronic Functional Materials, College of Chemistry and \\ Chemical Engineering, Anyang Normal University, Anyang 455000, China; 7180610011@stu.jiangnan.edu.cn \\ * Correspondence: liulin@aynu.edu.cn (L.L.); jxiuwang@csu.edu.cn (J.W.)
}

check for updates

Citation: Huang, Y.; Chang, Y.; Liu,

L.; Wang, J. Nanomaterials for Modulating the Aggregation of $\beta$-Amyloid Peptides. Molecules 2021, 26, 4301. https://doi.org/10.3390/ molecules26144301

Academic Editor: Adrian Keller

Received: 17 June 2021

Accepted: 9 July 2021

Published: 15 July 2021

Publisher's Note: MDPI stays neutral with regard to jurisdictional claims in published maps and institutional affiliations.

Copyright: (c) 2021 by the authors. Licensee MDPI, Basel, Switzerland. This article is an open access article distributed under the terms and conditions of the Creative Commons Attribution (CC BY) license (https:// creativecommons.org/licenses/by/ $4.0 /)$.

\begin{abstract}
The aberrant aggregation of amyloid- $\beta(\mathrm{A} \beta)$ peptides in the brain has been recognized as the major hallmark of Alzheimer's disease (AD). Thus, the inhibition and dissociation of $A \beta$ aggregation are believed to be effective therapeutic strategiesforthe prevention and treatment of AD. When integrated with traditional agents and biomolecules, nanomaterials can overcome their intrinsic shortcomings and boost their efficiency via synergistic effects. This article provides an overview of recent efforts to utilize nanomaterials with superior properties to propose effective platforms for $\mathrm{AD}$ treatment. The underlying mechanismsthat are involved in modulating $\mathrm{A} \beta$ aggregation are discussed. The summary of nanomaterials-based modulation of $A \beta$ aggregation may help researchers to understand the critical roles in therapeutic agents and provide new insight into the exploration of more promising anti-amyloid agents and tactics in AD theranostics.
\end{abstract}

Keywords: Alzheimer disease's; amyloid- $\beta$; nanomaterials; photothermal therapy; photodynamic therapy

\section{Introduction}

Abnormal changes in protein spatial structure can lead to the occurrence of protein conformational diseases [1]. For example, the precipitationand aggregation of protein amyloid fibers in neurons or brain parenchyma can induce cytotoxicity and eventually lead to neurodegenerative diseases, such as Alzheimer's disease (AD), amyotrophic lateral sclerosis (ALS), Huntington's disease (HD) and Parkinson's disease (PD) [2-5]. As the most common form of dementia, $\mathrm{AD}$ affects about 40 million people worldwide [6]. Although the pathogenesis of AD is multifactorial [7-11], the abnormal aggregation of $\beta$-amyloid $(A \beta)$ peptidesis still considered the most salient feature in AD. A $\beta$ peptides consisting of 39-43 amino acid residues are the proteolytic cleavage products of the $\beta$-amyloid precursor protein (APP) $[12,13]$. $A \beta_{1-40}$ and $A \beta_{1-42}$ are two major abundant types in amyloid plaques [14]. $A \beta$ monomers can assemble into $\beta$-sheet-rich oligomers with different sizes and form into long fibrils. Recent studies revealed that extracellular soluble $A \beta$ oligomers and fibrils exhibit strong neurotoxicity, which may be the potential targets for $\mathrm{AD}$ treatment [15]. Oxidative stress maybe the potential mechanism that explains the neurotoxicity induced by $A \beta$ aggregates [16]. Thus, the inhibition of $A \beta$ fibrillogenesis and the disassembly of $A \beta$ aggregates are considered to be important treatment strategies for AD.

Prompted by the need to pursue effective treatment of $A D$, many inhibitors against $A \beta$ aggregation and cytotoxicity were explored, including small molecules, peptides [17-19], proteins [20-22] and antibodies [23]. For example, we demonstrated that 5,10,15,20tetrakis(N-methyl-4-pyridyl)-porphyrin (TMPyP), a water-soluble porphyrin, can inhibit $A \beta$ aggregation, disintegrate the preformed $A \beta$ aggregates and alleviate $A \beta$-induced cytotoxicity [24]. Peptides with a special sequence that is homologous to $A \beta$ can keep it from aggregating through hydrophobic, hydrogen, covalent or electrostatic interactions, which 
are known as $\beta$-sheet breaker peptides, including LPFFD, KLVFFAE, CGGGGGIGLMVG and LVFFARK (LK7). It was suggested that denaturation of native $A \beta$ to oxygenated forms via photooxygenation could slow $A \beta$ aggregation and neurotoxicity [25]. Thus, various photosensitizers were explored for light-induced preclusion of $A \beta$ aggregation, such as methylene blue, porphyrins and riboflavin [26-29]. However, significant shortcomings limit the further application of these reagents, such as low solubility andpoor stability in physiological conditions. Moreover, the low permeability of the blood-brain barrier (BBB) also renders these inhibitors unsuitable for the treatment of AD [30]. Therefore, the demand is still urgent to develop effective drugs that target $A \beta$ aggregation with great clinical application potential.

With the development of nanotechnology in the past decades, numerous nanomaterials have been designed, synthesized and applied in different fields, such as physics, environmental science and biosensors. Due to the superb biocompatibility, stable physiochemical properties and synthesis and modification flexibility, nanomaterials-based approaches offer enormous potential to overcome the challenges in current therapeutic/diagnostic bio-reagents applications. In this regard, great efforts have been committed to discussing solutions from the nanomaterials perspective for improving AD treatment efficiency. Based on the characteristics of nanomaterials, traditional small molecule inhibitors can get across the BBB by being encapsulated into or modified with nanomaterials, such as mesoporous nano-selenium [31]. Furthermore, nanomaterials can be conjugated with target ligands, such as folate, polysaccharides, cell-penetrating peptidesand antibodies, to improve the bioavailability in brain regions and the efficiency of intracellular particles delivery [32,33]. Although there are a lot of studies that utilized different nanomaterials to inhibit the aggregation of the $A \beta$ peptide, their effects on peptide fibrillation still need to be investigated [34].

In this review, we focused on recent progress in nanomaterials-based methodology for inhibiting $A \beta$ aggregation. Meanwhile, we also paid close attention to novel strategies that use photo-sensitive or enzyme-mimicking properties in $\mathrm{AD}$ treatment.

\section{Nanomaterials}

According to the main composition and dimensions, the types of nanomaterialsfor modulating the aggregation of $\beta$-amyloid peptidesare various, including gold, carbon, transition oxide, two-dimensional (2D) nanomaterials, metal-organic framework (MOF) and self-assembled nanomaterials (Scheme 1).

\subsection{Gold-Based Nanomaterials}

Gold-based nanomaterials have the strengths ofbeing chemically inert, having tunable local surface plasmon resonance (LSPR) absorption and good conductivity. The LSPR absorption can be tuned by varying the size, shape, surrounding environment and dispersion state [35]. Owing to their unique properties and easeof manipulation, gold-based nanomaterials have broad applications in drug delivery, disease diagnosis and illness treatment, including central nervous system diseases [36]. The main category of gold nanomaterials that are used for treating AD includes bare gold nanoparticles (AuNPs) and gold nanocomposites modified with peptides or other molecules.

AuNPs were reported by many researchers as having functions of penetrating through the $B B B$, inhibiting $A \beta$ peptide from aggregation [37] and degrading $A \beta$ aggregates based on their size, surface charge, shape, functionality and even concentration [38-41]. For example, Ma et al. found that the negatively charged citrate-capped AuNPs could induce $\mathrm{A} \beta$ peptides to quickly form short protofibrils, subsequently causing them to assemble into short fibril bundles or even bundle conjunctions [42]. Wang and co-workers investigated the effect of AuNPs with different shapes on the aggregation of $A \beta_{1-40}$ peptides (Figure 1A) [43]. Moreover, because of the high degree of surface atomic unsaturation to adsorb $A \beta_{1-40}$ peptides with high affinity, Au nanospheres exhibited a more significant increase of the fibrillation process than Au nanocubes. Liu et al. investigated the size effect 
of gold nanorods (AuNRs) on modulating the kinetic process of $A \beta$ aggregation (Figure 1B) [44]. They found that the inhibition efficiency of larger AuNRs is better than that of smaller AuNRs and the rate constant was a quadratic function of the diameters or lengths. Liao et al. studied the effect of the surface charge of AuNPs on $A \beta$ aggregation [41]. As shown in Figure 1C, the negatively charged AuNPs could not only inhibit A $\beta$ fibrillization to form fragmented fibrils and spherical oligomers but also remodel preformed fibrils into smaller and ragged $A \beta$ species. Furthermore, by means of enhanced sampling molecular dynamics simulations, the interactions between $A \beta$ peptides and Au nanomaterials with various sizes and morphologies are well characterized, which is helpful for understanding the inhibition mechanism and explore new strategies for AD treatment $[45,46]$.

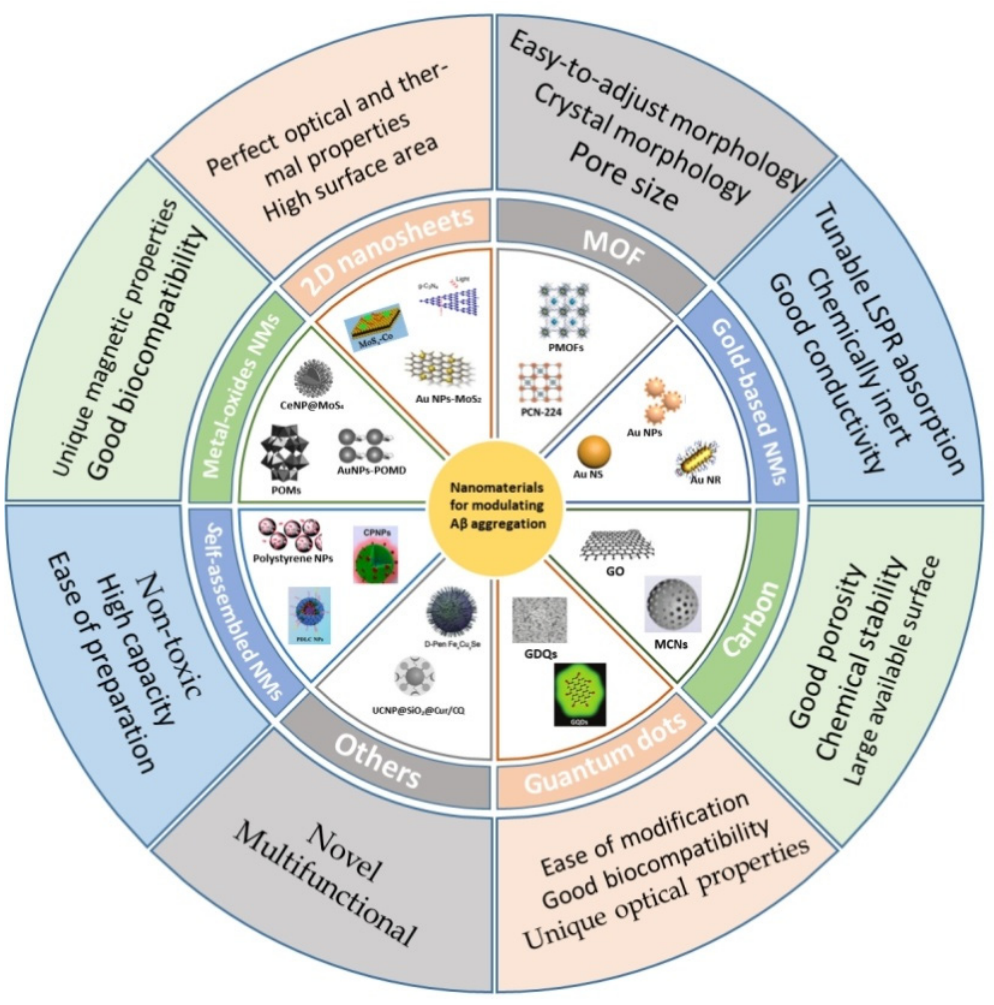

Scheme 1. A graphic summary with the important characteristics of nanomaterials discussedin this article.

Small molecules and peptides can be conjugated on the surface of nanomaterials to improve the properties and efficiency of both the modifiers and the nanomaterials [47]. For example, Palmal et al. prepared curcumin-functionalized AuNPs and found that watersoluble AuNPs with multiple curcumin moieties on the surface could inhibit $A \beta$ fibrillation and dissolve $A \beta$ fibrils without using other external agent or force [48]. $\beta$-Sheet breaker peptides can also be integrated with Au nanomaterials. Xiong et al. designed a branched dual-inhibitor sequence (VVIACLPFFD) for inhibiting A $\beta$ aggregation and cytotoxicity, whose inhibitory effects were greatly enhanced due to its special surface orientation and conformation (Figure 2A) [49]. However, it was also reported that $\mathrm{N}$-methylated peptides (CGGIGLMVG and CGGGGGIGLMVG) exhibit less effective inhibition of A $\beta$ fibril than free peptides because $\beta$-sheet $\mathrm{N}$-methylated peptides, with their more ordered arrangement on the surface, show weak affinity toward $A \beta$ in solution. In contrast, CLPFFD peptides modified on the nanoparticle surface can improve the stability of NPs, reduce the effect on cell viability and increase the delivery efficiency to the brain [50,51]. Moreover, the sequence of the peptide has an influence on the conjugation and stability of AuNPs and the affinity ability for $\mathrm{A} \beta$ fibrils [52]. 
A

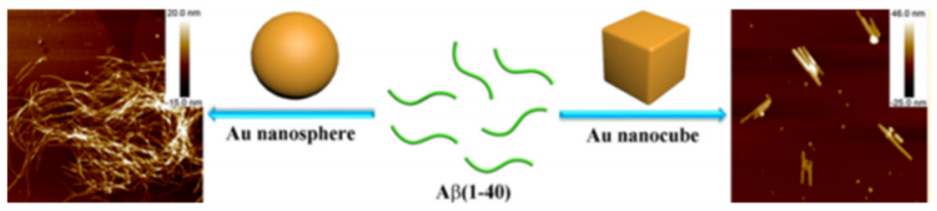

B

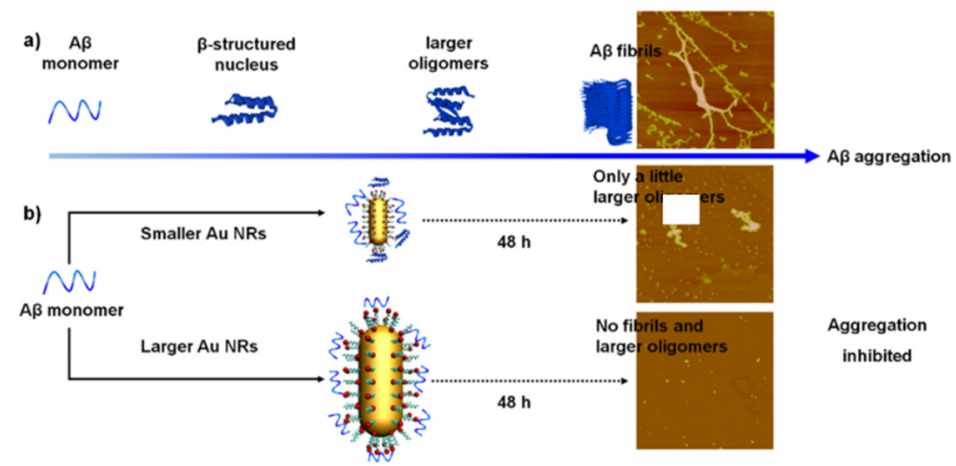

$\mathbf{C}$

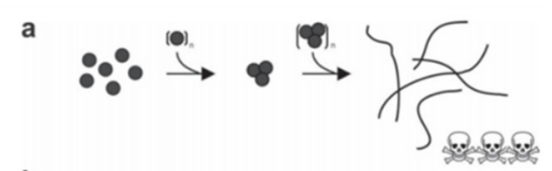

b

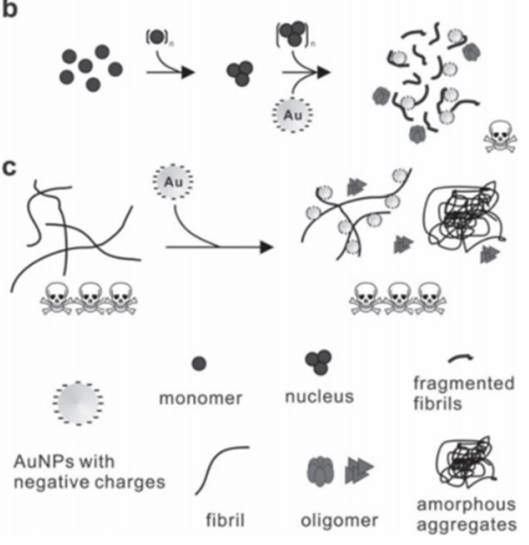

Figure 1. (A) Schematic of effects of gold nanospheres and nanocubes on $A \beta_{1-40}$ peptide fibrillation. Reprinted with permission from reference [43]. Copyright 2019 American Chemical Society. (B) Schematic of (a) the process of A $\beta$ aggregation and (b) The schematic of CTAB-stabilized AuNRs with different sizes inhibiting A $\beta$ peptides fibrillation [44]. Copyright 2019 Elsevier. (C) Diagram of A $\beta$ fibrillization pathways influenced by negatively charged AuNPs. (a) A $\beta$ monomers assemble into mature amyloid fibrils and cause neurotoxicity. (b) A $\beta$ monomers incubated with the AuNPs possessing negative surface potential lead to formation of short and fragmented fi brils along with spherical oligomers. The alteration rescues the toxicity generated from mature $A \beta$ fibrils. (c) AuNPs addition to preformed A $\beta$ fibrils induces ragged fi brils and amorphous aggregates without changing the toxicity level [41]. Copyright 2012 Wiley-VCH.

$\mathrm{A} \beta$ aggregation can be disintegrated via local heat generation. Kogan et al. found that AuNPs modified with Cys-PEP peptides and CLPFFD can selectively attach to the A $\beta$ fibrils and prefibrillar intermediate amyloidogenic aggregates (PIAA) (Figure 2B) [53,54]. Then, microwave irradiation generated local heat using nanoparticles to dissolve $A \beta$ aggregates. In photothermal therapy (PTT), light can be converted into heat with the aid of molecules or nanomaterialsthat display photothermal conversion ability. PTT was shown to be a promising strategy for the treatment of various diseases due to its remarkable advantages of site- and time-specificity, non-invasiveness and targeting selectivity. Owing to the extinction coefficient of theLSPR, Au nanomaterials can cause the photothermal ablation of amyloid peptide aggregates using laser irradiation $[50,55,56]$. As shown in Figure 2C, using penetratin peptide (Pen)-modified Au nanostars as part of an NIR photothermal method could be activated using ultralow irradiation to treat AD [57]. Due to the irregular morphology, Au nanostars possessed a high NIR absorption-scattering ratio and large specific surface area. Pen peptides can enhance the travel across the BBB and the cellular internalization of nanomaterials. The Pen-Au nanostars not only inhibited the formation of $A \beta$ fibrils but also disassembled the preformed $A \beta$ fibrils under the NIR irradiation. Moreover, a fluorescent ruthenium complex was loaded on the nanostars for tracking the drug delivery. To shorten the laser irradiation time, Lin et al. applied an NIR femtosecond laser for the destruction of the preformed AuNR-modified A $\beta$ fibrils (A $\beta$ fibrils@AuNRs) (Figure 2D) [58]. The results showed that in the presence of AuNRs, the femtosecondlaser irradiation could efficiently dissociate the $A \beta$ fibrils into small fragments with a non$\beta$-sheet structure in $5 \mathrm{~min}$ at a safe energy level and the morphology of AuNRs was transformed into amorphous shapes. However, there was no obvious destruction effect on the $\mathrm{A} \beta$ fibrils or $\mathrm{A} \beta$ fibrils@Au nanospheres under the laser irradiation. 

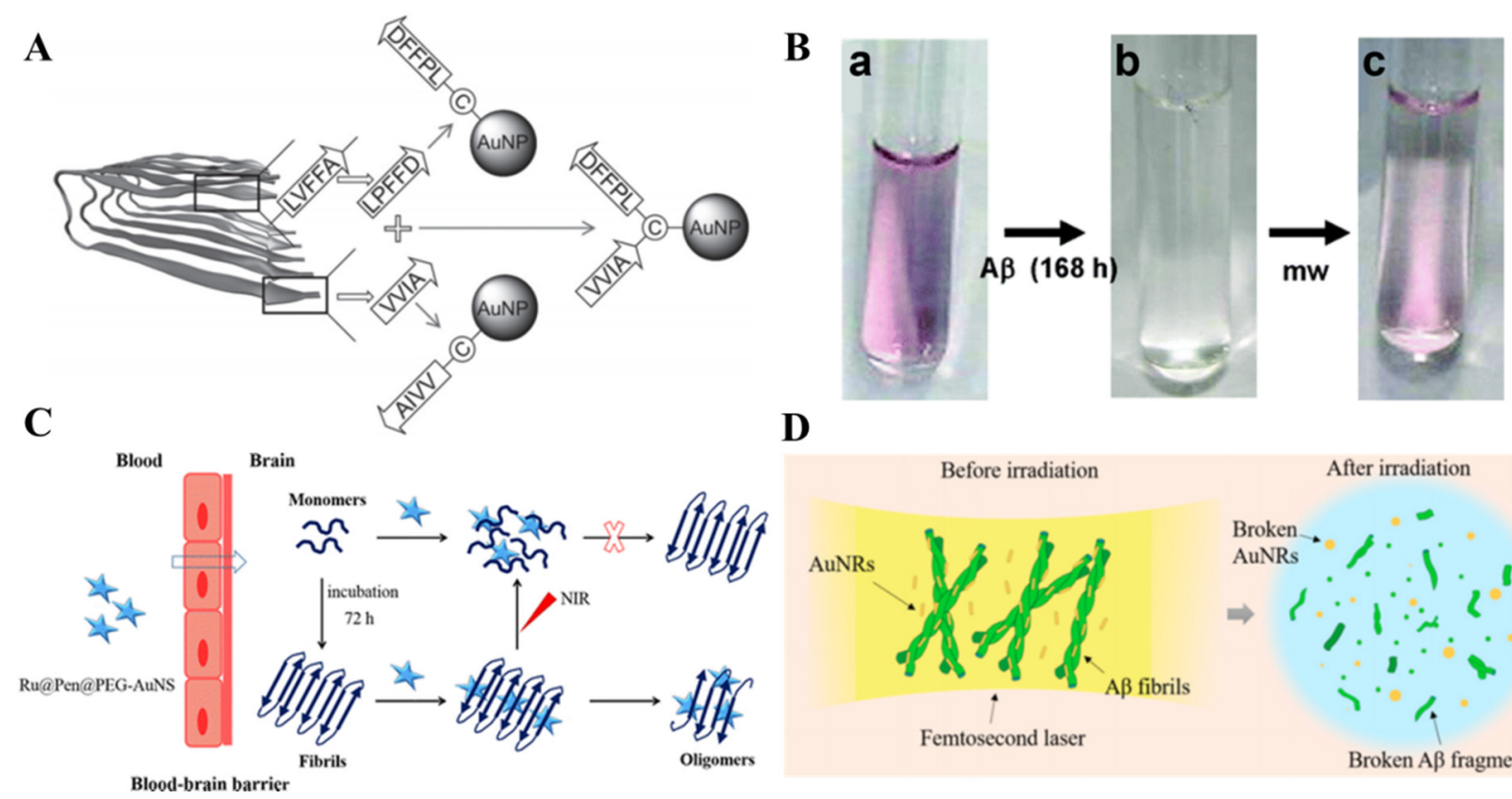

D

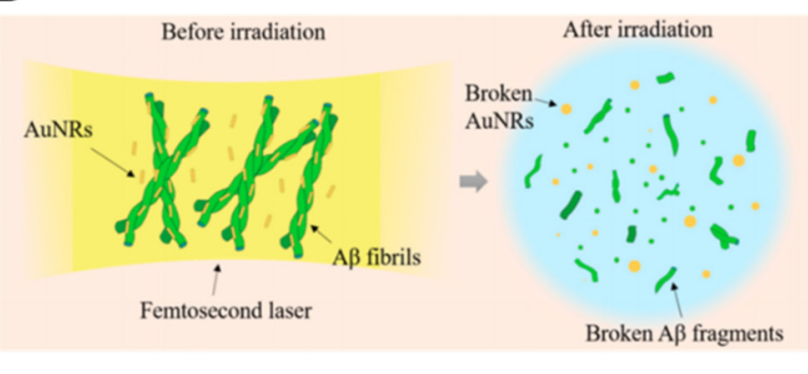

Figure 2. (A) Schematic of the design of peptide hybrid-functionalized AuNPs. Reprinted with permission from reference [49]. Copyright 2017 Wiley-VCH. (B) Schematic of remote dissolution of A $\beta_{1-42}$ precipitates. (a) AuNPCys-PEP solution mixed with $A \beta_{1-42}$ before the incubation. UVvis absorption peak at $527 \mathrm{~nm}$. (b) After incubation of AuNPCys-PEP with $A \beta_{1-42}$ for 7 days at $37^{\circ} \mathrm{C}$. No UV-vis absorption peak. (c) Irradiation of B for $8 \mathrm{~h}$ with $0.1 \mathrm{~W}$ and $12 \mathrm{GHz}$ microwave field. UV-vis absorption peak at $527 \mathrm{~nm}$. Reprinted with permission from reference [53]. Copyright 2006 American Chemical Society. (C) Schematic of Pen-modified Au nanostars for the NIR photothermal treatment of AD. Reprinted with permission from reference [57]. Copyright 2019 American Chemical Society. (D) Schematic of highly efficient destruction of amyloid- $\beta$ fibrils by femtosecond laser-induced nanoexplosion of gold nanorods. Reprinted with permission from reference [58]. Copyright 2016 American Chemical Society.

Metal ions, such as $\mathrm{Zn}^{2+}$ and $\mathrm{Cu}^{2+}$, were shown to participate in the pathology of AD [59,60]. A metal chelator can capture metal ions, hamper ROS formation and inhibit metal ion-induced $A \beta$ aggregation [61]. However, they have some disadvantages, such as poor permeability of the BBB and limited ability to distinguish toxic metal ions related to $A \beta$ aggregates from those associated with normal biological homeostasis $[62,63]$. Inspired by stimuli-responsive controlled-release drug delivery systems, the controllable release of chelators from "containers" may avoid this problem. Shi et al. reported a dual-responsive "caged metal chelator" release system based on NIR-absorbing Au nanocages [64]. As illustrated in Figure 3A, the chelator of clioquinol (CQ) was encapsulated in Au nanocages and the pore was blocked by human IgG via the redox- and thermal-sensitive arylboronic ester bond. Over-produced $\mathrm{H}_{2} \mathrm{O}_{2}$ that was induced by deviant $\mathrm{A} \beta$-metal ions aggregates would initiate the degradation of arylboronic ester and the subsequent release of CQ. Moreover, Au nanocages with NIR light could generate local heat to break the bond, thus enhancingthe $C Q$ release and dissolving $A \beta$ deposits via noninvasive remote control.

Unlike AuNPs, gold nanoclusters (AuNCs) consist of several to dozens of atoms that have excellent optical properties of intense fluorescence and high photostability. As shown in Figure 3B, Hao et al. found that AuNCs modified with CLVFFA via Au-S bonds showed improved inhibitory ability [65]. The results exhibited that AuNCs-CLVFFA could block the fibrillogenesis of $A \beta_{1-40}$ and the prolongation of fibrils and disaggregate the mature fibrils into oligomers. Zhang et al. found that Cys-Arg $(\mathrm{CR})$ dipeptide-caped $\mathrm{Au}_{23}(\mathrm{CR})_{14}$ NCs could completely dissolve exogenous mature $A \beta$ fibrils and endogenous $A \beta$ plaques and restore the natural unfolded state of $A \beta$ peptide from a $\beta$-sheet structure [66]. 
A (a)

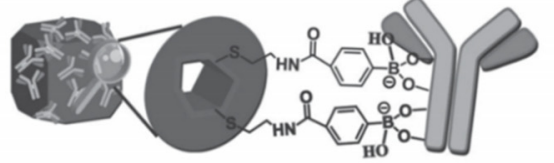

(b)

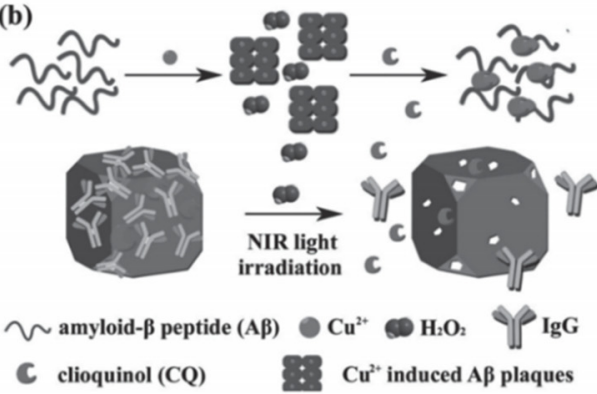

B

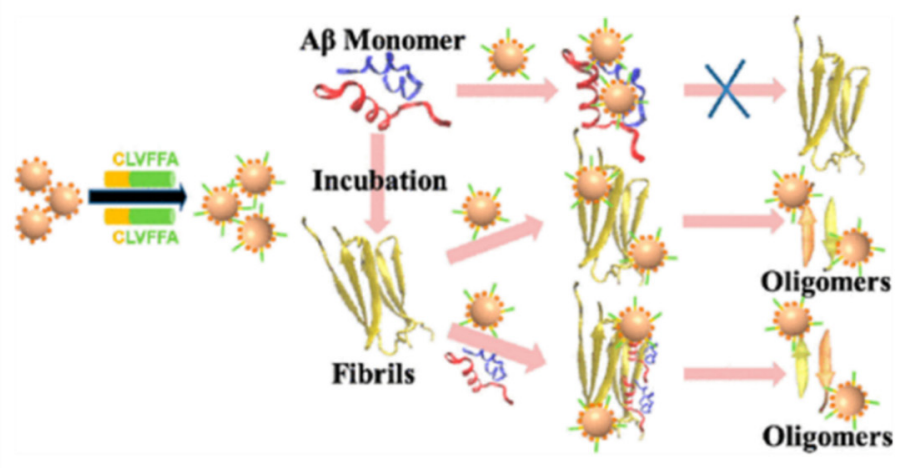

Figure 3. (A) (a) Illustration of IgG capped Au nanocages. (b) Schematic representation of $\mathrm{H}_{2} \mathrm{O}_{2}$-triggered and photothermalresponsive release of chelator CQ from IgG capped Au nanocages [64]. Copyright 2013 Wiley-VCH. (B) Schematic of CLVFFA-functionalized AuNCs for the inhibition of $A \beta$ fibrillation. Reprinted with permission from reference [65]. Copyright 2019 American Chemical Society.

\subsection{Carbon}

Carbon nanomaterials, including carbon nanotubes, graphene, fullerene, carbon nanospheres and carbon dots, have received great attention in the biological field due to their unique physical and chemical features. Carbon nanomaterials with hydrophobic surfaces can interact with various biomolecules, such as DNA, proteins and amyloid nanostructures. Moreover, when entering into a living organism, they may disturb the self-assembly processes of peptides or proteins.

\subsubsection{Graphene-Based Materials}

Owing to the large available surface and hydropathy, graphene oxide (GO) was applied to modulate the aggregation of $A \beta$ via the adsorption of amyloid monomers and decreasing the kinetic reaction [67-69]. Yang et al. found that pristine graphene and GO could inhibit $\mathrm{A} \beta$ peptide fibrillation and clear mature amyloid fibrils through experimental and computational investigation [70]. Mahmoudi et al. found that the formation of a protective protein corona on GO sheets could further enhance the inhibition effect [71]. The size effect of GO on modulating $\mathrm{A} \beta$ aggregation was also investigated by Wang and co-workers [72]. Surface chirality was also shown to play an important role in protein adsorption dynamics and cell behaviors. As shown in Figure 4A, Qing et al. studied the chiral effect on amyloid formation by using cysteine-enantiomer-modified GO as a platform [73]. The result showed that $R$-cysteine-modified GO suppressed the absorption, nucleation and fiber elongation processes of $A \beta_{1-40}$, thus leading to a remarkable inhibition rate of amyloid fibril formation. However, $s$-cysteine-modified GO accelerated these processes. The stereoselective interaction between chiral moieties and $\mathrm{A} \beta$ peptides caused the enrichment of oligomers on the GO surface, but the distance between them should be short enough $(1-2 \mathrm{~nm})$. This work provided novel insights into understanding the key roles of biological membranes on protein amyloidosis.

Based on its high optical absorption in the NIR region, graphene has been widely explored in biomedical applications. In 2012, Li et al. first reported the photothermal treatment of AD by using thioflavin-S (ThS)-modified GO (Figure 4B) [74]. The ThSmodified GO can produce local heat to dissociate $A \beta$ fibrils under low-power NIR laser irradiation with improved selectivity because of the specific targeting of ThS toward amyloid. Moreover, the $\mathrm{A} \beta$ morphology change during the photothermal treatment can be monitored in real time by recording the increased fluorescence of ThS in the complex of ThS and $A \beta$ fibrils. Taking advantage of the permeation and disruption of the cellular membrane by $\mathrm{A} \beta$ oligomers, $\mathrm{Xu}$ et al. developed an oligomer-self-triggered and NIR- 
enhanced system based on the lipid-bilayer-coated graphene (GMS-Lip) [75]. Dyes and drugs were co-loaded within GMS-Lip, which could be released by the amyloid oligomers. In addition, thermal-sensitive Lip could be further destroyed by the heat produced by graphene under an NIR laser to ensure the release efficiency. Moreover, the NIR-assisted release could be initiated locally by tracking the fluorescence.

GO can hybridize with other nanomaterials to achieve improved inhibition performance based on the synergistic effect. Moreover, the decoration of nanomaterials on GO can avoid the easy agglomeration and restacking of GO. For instance, GO/AuNPs nanocompositeswere prepared using pulsed laser ablationin water to reduce $\mathrm{A} \beta$ aggregation, which produced an enhanced effect compared with using GO or AuNPsalone [76]. Due to the hydrophobic interactions between the nanocomposites with hydrophobic amino acids of $A \beta_{1-42}$, the nucleation process was significantly disturbed and the fibrillation was subsequently slowed. The result showed that the GO/AuNPs nanocomposites not only reduced $A \beta_{1-42}$ aggregation and cytotoxicity but also led to the deploymerization of amyloid fibrils and inhibition of their cellular cytotoxicity. In addition, Ahmad et al. reported that a GO- $\mathrm{Fe}_{4} \mathrm{O}_{4}$ nanocomposite showed the enhanced inhibitory effect of $\mathrm{A} \beta_{1-42}$ peptides and depolymerized $A \beta_{1-42}$ fibrils (Figure $4 \mathrm{C}$ ) [77].

$\mathbf{A}$

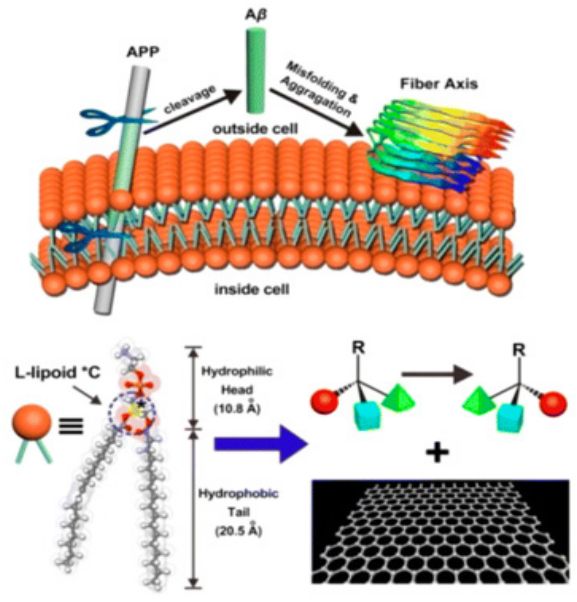

B

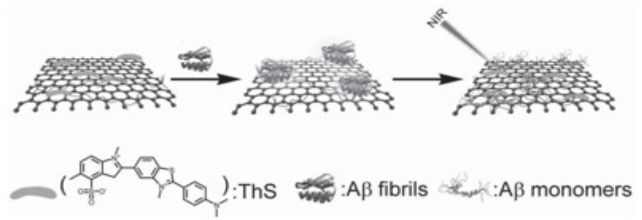

C
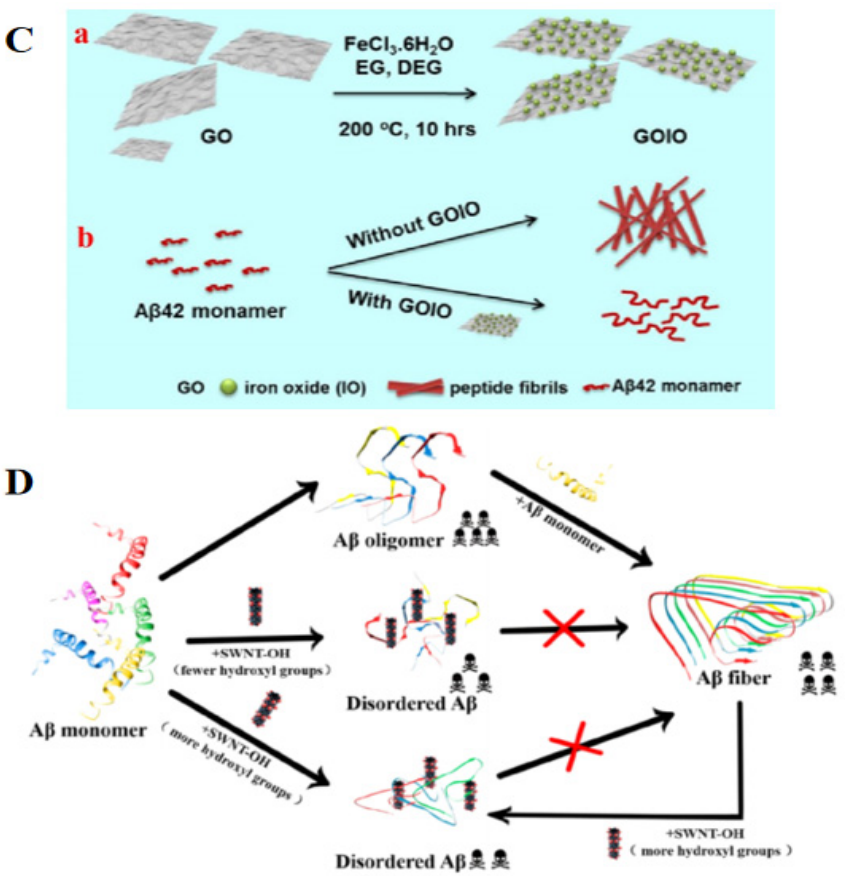

Figure 4. (A) Schematic representation of the chiral effect at the protein/graphene interface to understand amyloid formation. Reprinted with permission from reference [73]. Copyright 2014 American Chemical Society. (B) Schematic representation of ThS-modified GO with high NIR absorbance used for AD treatment. Reprinted with permission from reference [74]. Copyright 2012 Wiley-VCH. (C) Schematic representation of the (a) preparation of GOIO and (b) modulation of $A \beta_{1-42}$ aggregation using GOIO. Reprinted with permission from reference [77]. Copyright 2012 Elsevier. (D) Schematic representation of the effect of SWNT-OH on $A \beta$ aggregation. Reprinted with permission from reference [78]. Copyright 2019 American Chemical Society.

\subsubsection{Carbon Nanotubes (CNTs)}

CNTs are tubular structures of rolled-up sheets of graphene, including single-wall (SWCNTs) and multi-wall (MWCNTs) species. CNTs can be exploited for biosensing, tissue engineering and drug delivery due to their chemical stability, good porosity and high surface area. Moreover, SWCNTs were shown to shuttle drugs into a wide range of cell types $[79,80]$. Luo et al. found that SWNTs can induce $A \beta$ peptides to form $\beta$-sheet-rich yet non-amyloid fibrils, and A $\beta$ peptidescan reduce the toxicity of SWNTs [80]. However, the 
poor dispersibility of pristine SWNTs in solution greatly decreased the inhibition efficiency. Functionalization of SWNTs with hydrophilic groups may increase their dispersibility. Liu et al. investigated the inhibitory effect of SWNT-OH on $A \beta_{1-42}$ fibrillogenesis [78]. As shown in Figure 4D, the percentage of hydroxyl groups in SWNT-OH was crucial for their inhibition capacity against $A \beta_{1-42}$ aggregation. Moreover, SWNT-OH could transform the mature fibrils into smaller granular aggregates but not oligomers. Xie et al. revealed that the electrostatic, hydrophobic and aromatic stacking interactions between hydroxylated SWCNT and $A \beta_{16-22}$ not only inhibit the $A \beta_{16-22}$ fibrillization but also shifted the conformations of oligomers from the ordered $\beta$-sheet-rich structures into the disordered coil aggregates [81].

\subsubsection{Carbon Nanospheres}

Phototherapy, including photothermal therapy (PTT) and photodynamic therapy (PDT), is generally activated by visible or first NIR-I light. However, it has limited tissue penetration through dense skull and scalp and may cause damage to nearby normal tissues. Thus, utilizing excitation light at second near-infrared light (NIR-II, 1000-1700 nm) is a more attractive option for deeper tissue penetration and a lower signal-to-noise ratio. Ma et al. designed $\mathrm{A} \beta$ targeting, $\mathrm{N}$-doped three-dimensional mesoporous carbon nanospheres (KD8@N-MCNs) for NIR-II PTT of AD (Figure 5A) [82]. KLVFFAED (KD8) was used as the target of $A \beta$ and receptor of the advanced glycation end-products (AGEs). N-MCN was selected as the NIR-II photothermal agent due to its excellent photothermal effect and superoxide dismutase (SOD) and catalase (CAT)-like activities. Combining the above advantages, KD8@N-MCNs can dissolve $\mathrm{A} \beta_{1-42}$ aggregates under NIR-II illumination, scavenge intracellular ROS and alleviate neuroinflammation in vivo. Moreover, KD8@N-MCNs can efficiently cross the BBB due tothe modification of KD8 on the nanosphere's surface.

\subsubsection{Fullerene}

Fullerene possesses the advantages of strong hydrophobicity and high electrophilicity, which endow it with the potential ability to inhibit the aggregation of $A \beta$ peptides [83]. For example, Xie et al. investigated the molecular mechanism of fullerene-based inhibition, which could be attributed to the strong hydrophobic and aromatic-stacking interactions between the fullerene hexagonal rings and the Phe rings of $A \beta_{16-22}$ peptide [84]. Moreover, Kim et al. reported that a $\mathrm{C}_{60}$ derivate (1,2-dimethoxymethanofullerene) could bind to the central motif, namely, $A \beta_{16-20}$ (KLVFF), based on the strong hydrophobic interaction and inhibit the aggregation of $A \beta$ peptides at the early stage [85]. After that, other $C_{60}$ derivates were also synthesized and applied for inhibiting the aggregation of $\mathrm{A} \beta$ peptides, including hydroxylated fullerene and sodium fullerenolate $\mathrm{Na}_{4}\left[\mathrm{C}_{60}(\mathrm{OH})_{\sim 30}\right]$ [86-90].

$\mathrm{C}_{60}$ could produce reactive oxygen species (ROS) viathe photo-excitation of $\mathrm{C}_{60}$ and $\mathrm{O}_{2}$ to stimulate DNA and protein photocleavage [91,92]. Ishida et al. employed a $\mathrm{C}_{60}$-sugar hybrid to inhibit $A \beta$ aggregation and degrade $A \beta$ oligomers under long-wavelength $U V$ radiation and neutral conditions [93]. Besides the hydrophobic interaction between $A \beta$ and $\mathrm{C}_{60}$, the hydrophilic sugar can interact with the hydrophilic N-terminal of $\mathrm{A} \beta_{1-42}$ through the formation of hydrogen bonds. Aiming to improve the solubility, $\mathrm{C}_{60}$ was functionalized with a sulfo or amino group [94]. These two hydrophilic groups could further strongly interact with the termini of $A \beta_{1-42}$ through the ionic interactions and/or hydrogen bonds.

In addition to generating ROS under photo-excitation, $\mathrm{C}_{60}$ can be used as a ROS scavenger in the dark. Du et al. designed a NIR-switchable nanoplatform for synergy therapy of $\mathrm{AD}$ based on the ROS-generating and -quenching properties of $\mathrm{C}_{60}$ [95]. As shown in Figure $5 B$, UCNPs were conjugated with $C_{60}$ and the $A \beta$-target peptide KLVFF. Under NIR irradiation, $\mathrm{C}_{60}$ was photo-sensitized using UCNPs through FRET to produce ROS, leading to the oxygenation of $A \beta$ and inhibition of its aggregation. In the dark, $C_{60}$ could eliminate the overproduced ROS to protect the cell from oxidative stress. 
$\mathbf{A}$

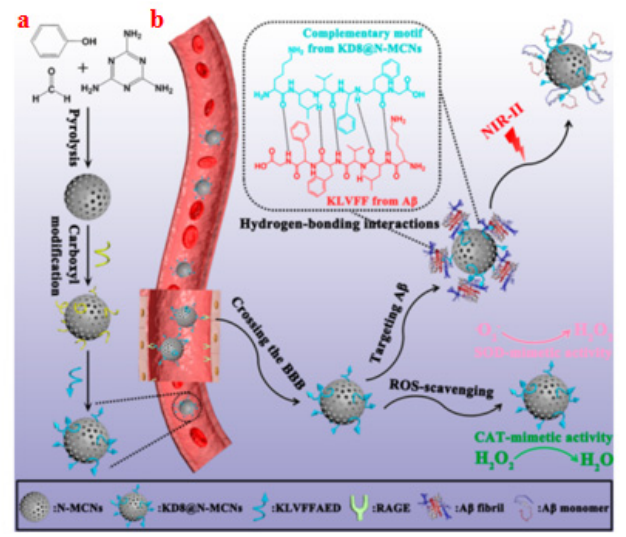

B

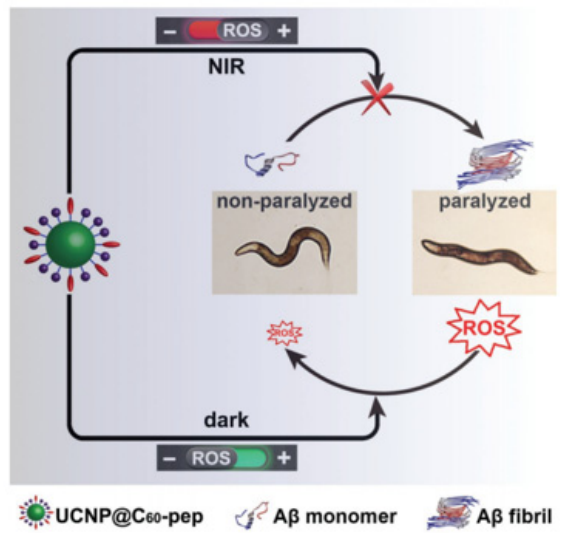

Figure 5. (A) (a) Schematic chart of KD8@N-MCNs synthesis and (b) schematic diagram of the KD8@N-MCNs mechanism of action. Reprinted with permission from reference [82]. Copyright 2020 American Chemical Society. (B) Schematic of UCNP@ $\mathrm{C}_{60}-\mathrm{PEP}$ inhibiting A $\beta$ aggregation in vivo and attenuating the oxidative stress to prolong the lifespan of the CL2006 strain. Reprinted with permission from reference [95]. Copyright 2018 Wiley-VCH.

\subsubsection{Carbon Dots}

Since being accidentally discovered as byproducts during the purification of SWCNTs, carbon dots (CDs) have received growing interest in biomedical and biosensing fields [96]. As a potential alternative to semiconductor QDs, CDs have prominent characteristics, such as their low cost, ease of synthesis, good biocompatibility and intrinsic fluorescence. Moreover, the absorption and emission spectra can be tuned by adjusting the degree of carbonization and the percentage of surface moieties.

CDs generally have abundant functional groups on their conjugated aromatic core, such as hydroxyl, amino and carboxyl groups. They can interact with $\mathrm{A} \beta$ peptides and aggregates through electrostatic, hydrogen bonding, $\pi-\pi$ stacking and hydrophobic interactions because of their abundant surface chemical properties and small size (generally less than $10 \mathrm{~nm}$ ). Liu et al. demonstrated that graphene quantum dots (GQDs) can inhibit $A \beta_{1-42}$ peptide aggregation, mainly via hydrophobic interactions, and rescue $A \beta_{1-42}$ oligomer-induced cytotoxicity [97]. The surface chirality of nanoparticles also has an influence on the inhibition efficiency against $A \beta$ aggregation [98]. L-Lys-CDs were reported to exhibit a higher affinity toward $A \beta_{1-42}$ peptides than D-Lys-CDs and could remodel the $A \beta_{1-42}$ secondary structure and fibril morphologies [99]. CDs can cross the BBB because of their small size, which allows them to be utilized as nano-carriers to transport functional molecules to the brain. Thus, GQDs conjugated with an endogenous neuroprotective glycine-proline-glutamate peptide showed an enhanced neuroprotective effect and improved learning and memory capability of APP/PS1 mice [100]. CDs can also be used as fluorescent nanoprobes for biological imaging. Among them, CDs with red fluorescence possess several advantages of low biological fluorescence background signal and high tissue penetration ability. Recently, Gao et al. discovered new functions of nitrogen-doped carbonized polymer dots (CPDs) to target $A \beta$ aggregation [101]. The non-covalent interactions between $A \beta$ aggregates and CPDs limited the molecular vibration and rotation of $C P D s$, resulting in the red emission. As shown in Figure $6 \mathrm{~A}$, after interacting with $\mathrm{A} \beta$ fibrils, CPDs emitted an increased red fluorescence signal, indicating that CPDs can be utilized as a multifunctional therapeutic agent for disintegrating and monitoring $\mathrm{A} \beta$ fibrils.

Photoexcited CDs can generate reactive oxygen species (ROS) through energy-transfer and electron-transfer pathways, which endows them with the ability to denature toxic biomolecules. For example, branched polyethylenimine-passivated CDs (bPEI@CDs) were reported as photosensitizers that inhibit the self-assembly of $A \beta$ peptide and disassemble preformed $A \beta$ aggregates upon light irradiation (Figure 6B) [102]. Photoactivated bPEI@CDs produced ROS to oxygenate and break $\beta$-sheet-rich $A \beta$ aggregates into smaller fragments. Meanwhile, it was more efficient for reducing A $\beta$-mediated toxicity compared with bPEI@CDs under dark conditions. However, 
the UV-to-Vis dependent photoexcitation is a potential obstacle to the use of bPEI@CDs. To improve the effectiveness of photoexcitation of CDs and grant the ability to target $A \beta$, red-lightresponsive DNA aptamer-functionalized CDs (Apta@CDs) were designed for the A $\beta$-targeting spatiotemporal suppression of A $\beta$ aggregation [103]. As shown in Figure 6C, Apta@CDs could specifically bind to $\mathrm{A} \beta$ aggregates in the 5xFAD (five familial Azheimer's) mouse brain. Photoexcited Apta@CDs under red LED $(617 \mathrm{~nm})$ light can generate ${ }^{1} \mathrm{O}_{2}$, denature the $\mathrm{A} \beta$ peptide, slow the formation of $\beta$-sheet-rich aggregates and alleviate the $A \beta$-associated cytotoxicity.

A
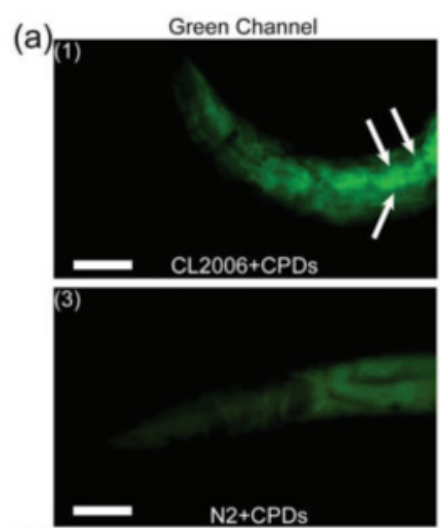

(b)(1)
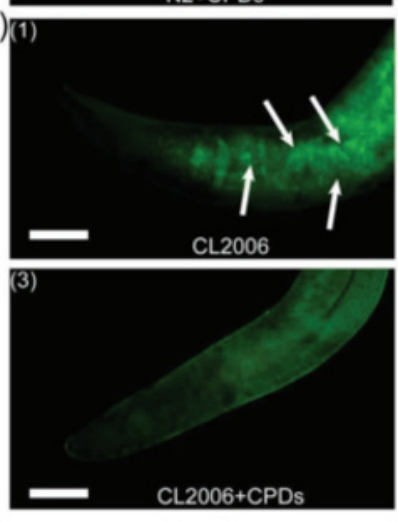
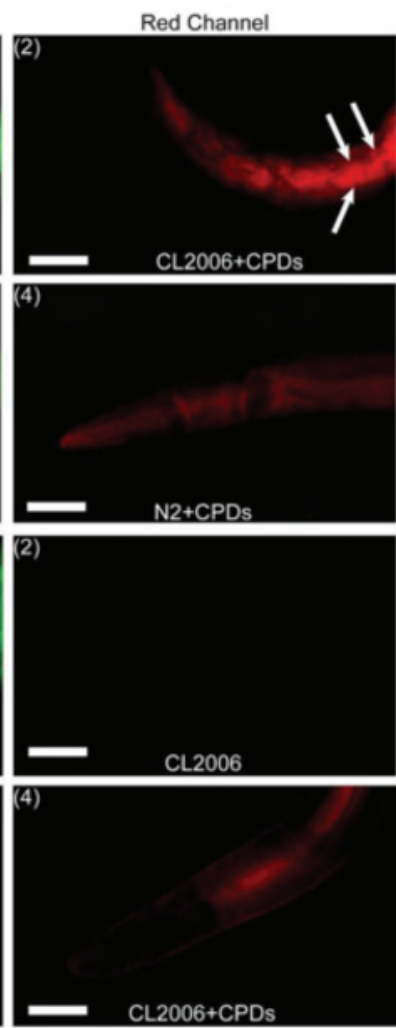

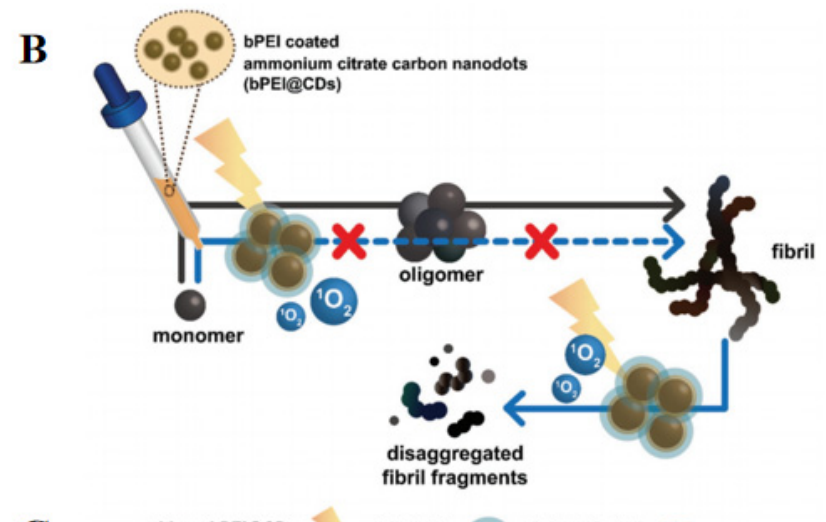

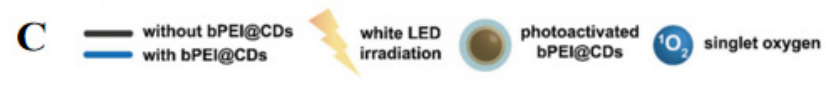

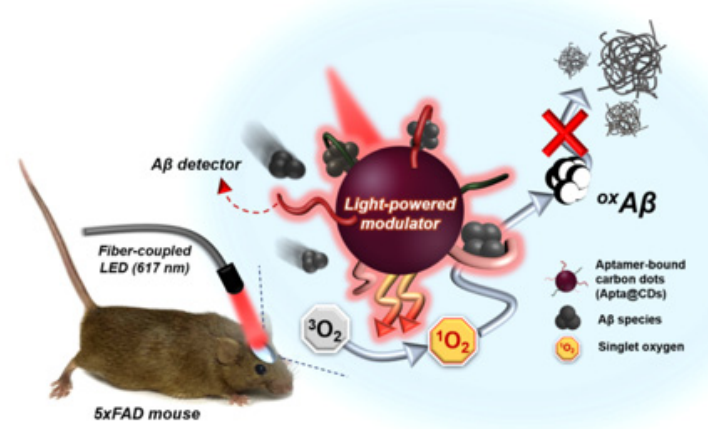

Figure 6. (A) In vivo assays with C. elegans (CL2006 and N2). (a) Fluorescence images of CL2006 (a1,a2) and N2 (a3,a4) nematodes that were co-stained with ThT and CPDs. (b) Fluorescent images of inhibiting A $\beta$ deposits after treating without (b1,b2) or with (b3,b4) CPDs in CL2006 nematodes. Reprinted with permission from reference [101]. Copyright 2020 WileyVCH. (B) Schematic of bPEI@CDs' capabilities regarding inhibiting A $\beta$ assembly and disaggregating preformed fibrillar aggregates. Reprinted with permission from reference [102]. Copyright 2017 Wiley-VCH. (C) Schematic of A $\beta$-targeting, CD-mediated photomodulation modality for the spatiotemporal inhibition of $A \beta$ aggregation in vivo. Reprinted with permission from reference [103]. Copyright 2020 American Chemical Society.

\subsection{Metal-Oxide Nanomaterials}

\subsubsection{Magnetic Nanoparticle (MNPs)}

MNPs have the advantages of good biocompatibility and unique magnetic properties. Theywere deemed as therapeutics and imaging agents inthe treatment of brain diseases. Mahmoudi et al. investigated the physicochemical effects (size, charge and surface treatment) of coated superparamagnetic iron oxide nanoparticles (SPIONs) on A $\beta$ aggregation (Figure 7A) [104]. They found that the size and surface area have significant effects on $\mathrm{A} \beta$ fibrillation. Lower concentrations of SPIONs inhibited the fibrillation and higher concentrations promoted the rate, reversely. Furthermore, the positively charged SPIONs promoted fibrillation at significantly lower particle concentrations. In addition, peptideand antibody-modified MNPs also significantly inhibited A $\beta$ fibrillation $[105,106]$.

MNP-based targeted tissue drug delivery was shown to be a promising therapeutic approach because MNPs can be directed toward a specific site in disease tissue locations 
by a magnetic force. Mesoporous silica-coated MNPs (MMSNPs) were utilized as smart vehicles to encapsulate quercetin $(\mathrm{QC})$ with anti-amyloid and antioxidant properties, overcoming the limitations of poor solubility and bioavailability (Figure 7B) [107]. They found that biophenols $Q C$ can bind with $A \beta$ monomers and oligomers to block the fibril formation [108]. Moreover, the released QCs could decrease the A $\beta$-related cytotoxicity and minimize the $\mathrm{A} \beta$-induced ROS. Li et al. designed light-responsive magnetic nanoparticle prochelator conjugates for inhibiting metal-induced $A \beta$ aggregation [109]. In this complex, $\mathrm{Fe}_{3} \mathrm{O}_{4}$ NPs were utilized to cage CQ through a photoactive o-nitrobenzyl bromide (ONB) linkage and the conjugates did not interact with $\mathrm{Cu}^{2+}$ in the prochelator form. After the photolytic cleavage under UV radiation at $365 \mathrm{~nm}$, the caged CQ was liberated from the NPs, efficiently preventing metal-induced $A \beta$ aggregation, decreasing cellular reactive oxygen species (ROS) and protecting cells against $A \beta$-related toxicity.

A

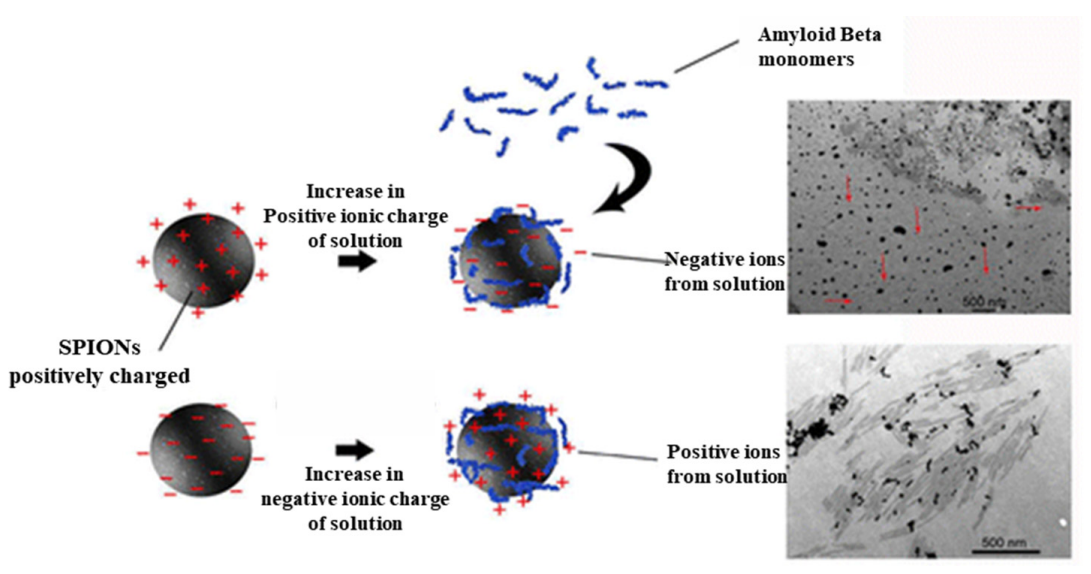

B
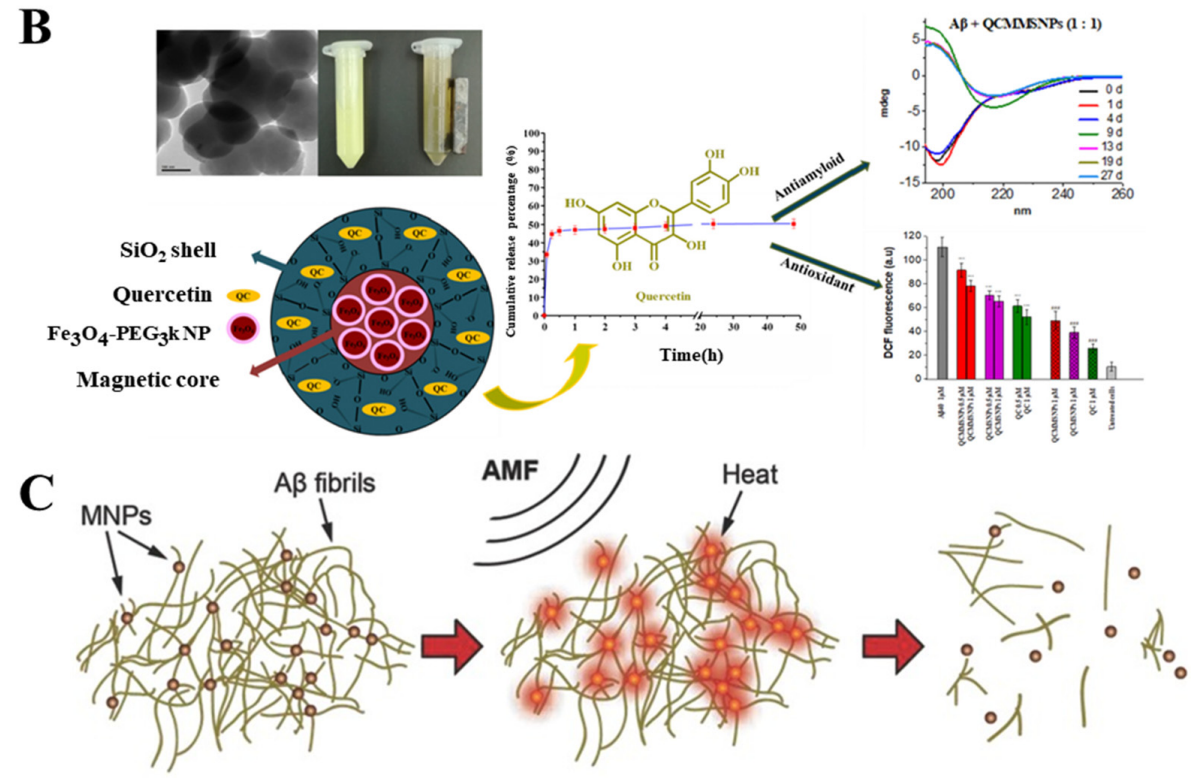

Figure 7. (A) Schematic of the influence of the physiochemical properties of SPIONs on A $\beta$ fibrillation in solution. Reprinted with permission from reference [104]. Copyright 2013 American Chemical Society. (B) Schematic of the encapsulation of QC in MMSNPs, which enhances its aqueous solubility and its effect on $A \beta$ aggregation. Reprinted with permission from reference [107]. Copyright 2020 Elsevier. (C) Schematic of a method for remote protein disaggregation using AMF and MNPs. Reprinted with permission from reference [110]. Copyright 2012 American Chemical Society.

Previous studies indicated that MNPs can effectively improve the local temperature in the area extremely close to the MNPs (about $5 \mathrm{~nm}$ ) through alternating the magnetic field, which reduces the penetration depth limit and damage to the neighboring tissues $[111,112]$. 
Therefore, it is a non-invasive strategy for clearing A $\beta$ aggregates by using MNPs/AMF hyperthermia [113]. For instance, Loynachan et al. used LPFFD-functionalized PEG-coated MNPs forthe remote magnetothermal disruption of $A \beta$ aggregates under a high-frequency alternating magnetic field (AMF) (Figure 7C) [110]. They found that the local heat dissipated by targeted MNPs could dramatically decrease the size of $A \beta$ aggregates from microns to tens of nanometers upon exposure to a physiologically safe AMF, which isattributed to the dissociation of $A \beta$ deposits. The reduced $A \beta$ cytotoxicity due to the magnetothermal disruption was confirmed in primary hippocampal neuronal cultures. Moreover, for simultaneous diagnosis and treatment, an $\mathrm{A} \beta$ oligomer-sensitive naphthalimide-based fluorescent probe (NFP) was loaded on the KLVFF-conjugated MNPs [114].

\subsubsection{Polyoxometalates (POMs)}

Polyoxometalates (POMs) are early-transition-metal-oxygen-anion clusters that usually include the $\mathrm{d}^{0}$ species $\mathrm{V}(\mathrm{V}), \mathrm{Nb}(\mathrm{V}), \mathrm{Ta}(\mathrm{V}), \mathrm{Mo}(\mathrm{VI})$ and $\mathrm{W}(\mathrm{VI})$ with versatile structures. They have been widely explored in recent years for biomedical applications [115] and showed remarkable effects against acquired immune deficiency syndrome (AIDS) [116]. Because of the similarity to water-solubilized fullerene derivatives, POMs can be utilized as $A \beta$ aggregation inhibitors. For example, Li et al. identified four POMs with the sizedependent ability of inhibiting $\mathrm{A} \beta$ peptide aggregation via a high-throughput screening method, in which $\mathrm{K}_{8}\left[\mathrm{P}_{2} \mathrm{CoW}_{17} \mathrm{O}_{61}\right]$ with a Wells-Dawson structure exhibits the highest inhibition (Figure 8A) [117]. They also found that POMs electrostatically bind to the cationic $\mathrm{His}_{13}-\mathrm{Lys}_{16}$ cluster (HHQK) of A $\beta$ peptides. Zhou et al. demonstrated that two POMs with the wheel-shaped Preyssler structure and the Keggin-type structure could interact with $A \beta_{1-40}$ and inhibit its fibrillization [118]. To suppress the peroxidase-like activity of $\mathrm{A} \beta$-hemin, POM-Dawson was further functionalized with transition metal ions of various histidine-chelating metals. These transition metalPOMs not only specifically targeted the HHQK in $A \beta$ peptides but also showed a stronger inhibition effect on $A \beta$-hemin formation [119]. After that, organoplatinum-substituted POMs were reported to inhibit $A \beta$ aggregation [120]. Moreover, POMs can also significantly inhibit metal-ion-induced $A \beta_{1-40}$ aggregation because POMs with high negative charges show strong interactions with $\mathrm{Zn}^{2+}$ and $\mathrm{Cu}^{2+}[121]$.

POMs have been broadly used for homogeneous photocatalysis in water to produce ROS and oxidize various substrates, including pyrimidine bases [122,123]. Inspired by this fact, Li et al. demonstrated that POMs can photodegrade $\mathrm{A} \beta$ monomers and even oligomers under photoirradiation conditions [124]. At a low concentration, POMs still showed ahigh inhibition efficiency under UV irradiation. To disaggregate the neurotoxic $\mathrm{A} \beta$ fibrils, Li et al. further developed a redox-activated NIR-responsive reduced POMs (rPOM)-based agent for the photothermal treatment of AD (Figure 8B) [125]. In this work, mesoporous silica nanoparticles (MSNs) were used to load rPOM and thermally responsive copolymer poly(N-isopropylacrylamide-co-acrylamide) was employed to cap the pores of MSNs to prevent rPOMs leakage and ensure they remained intact. When being irradiated by an $808 \mathrm{~nm}$ laser, rPOMs with strong NIR absorption produced local hyperthermia to melt the shell away from the channels, which would inhibit $A \beta$ aggregation and disaggregate $\mathrm{A} \beta$ fibrils by local heat. Moreover, $\mathrm{rPOM}$ could act as antioxidants to clear ROS and the product of POMs can inhibit $\mathrm{A} \beta$ aggregation. 
A

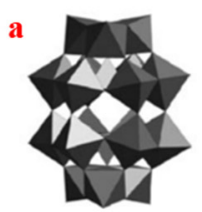

b

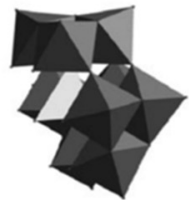

B

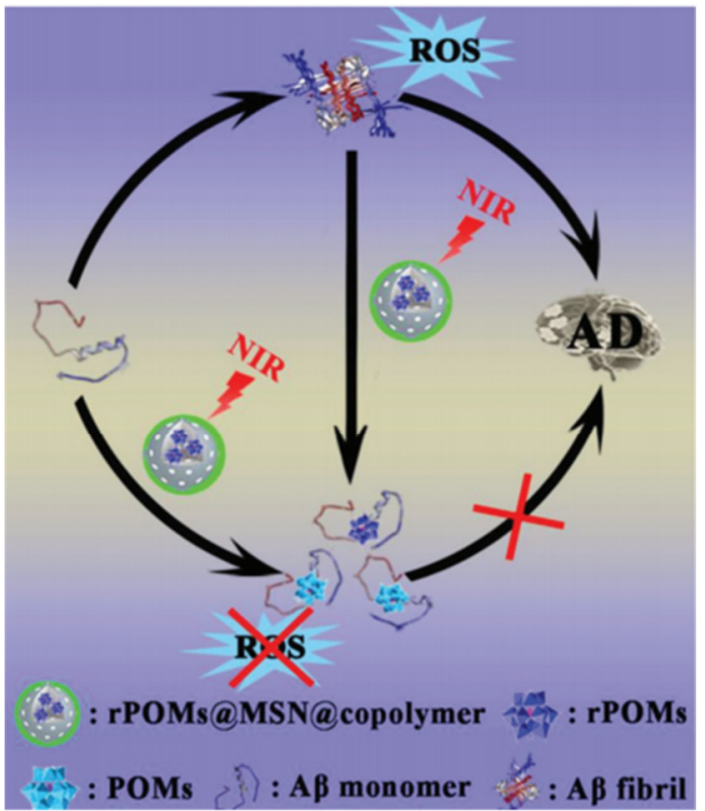
c
C

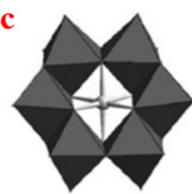

D

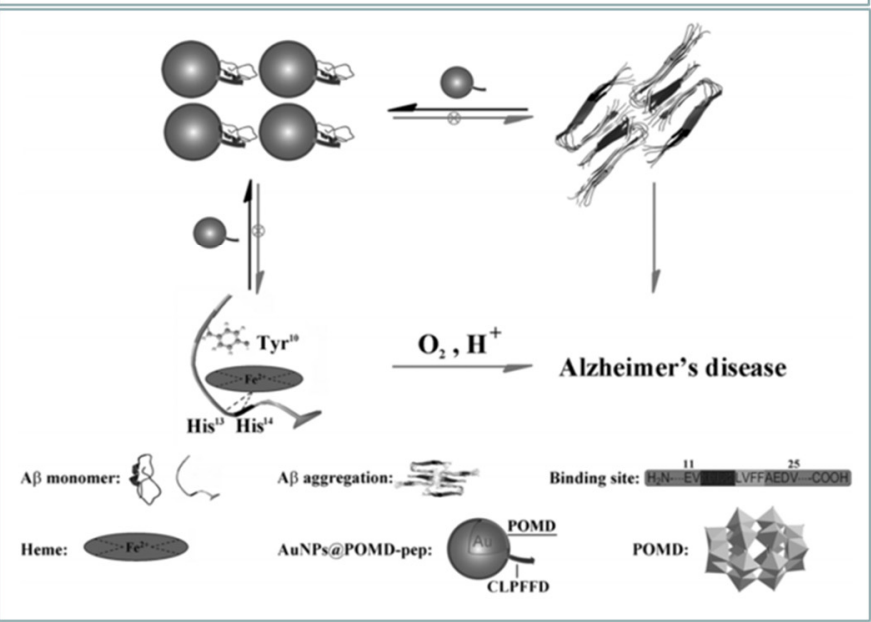

Figure 8. (A) Schematic of the structures of typical polyoxometalates: (a) Wells-Dawson structure, $\mathrm{K}_{8}\left[\mathrm{P}_{2} \mathrm{CoW}_{17} \mathrm{O}_{61}\right]$; (b) trivacant Keggin structure, $\alpha-\mathrm{Na}{ }_{9} \mathrm{H}-\left[\mathrm{SiW}_{9} \mathrm{O}_{34}\right]$; (c) Anderson structure, $\mathrm{Na}_{5}\left[\mathrm{IMo}_{6} \mathrm{O}_{24}\right]$. Reprinted with permission from reference [117]. Copyright 2011 Wiley-VCH. (B) Schematic of the NIR-responsive rPOMDs@MSNs@copolymer acting as a multifunctional photothermal agent for the treatment of AD. Reprinted with permission from reference [125]. Copyright 2018 Wiley-VCH. (C) Schematic of the peptide-POM conjugates used for AD treatment. (a) The schematic illustration of self-assembly of $A \beta 15-20$ and POM to hybrid spheres. (b) The assembled peptide and POM nanoparticles can effectively inhibit $A \beta_{1-40}$ aggregation. Reprinted with permission from reference [126]. Copyright 2013 Wiley-VCH. (D) Schematic of the A $\beta$ pathway influenced by AuNPs@POMD-peptide. Reprinted with permission from reference [127]. Copyright 2015 Wiley-VCH.

POMs can be employed as inorganic nanobuilding blocks to fabricate organic-inorganic assembly nanoarchitectures with the aid of peptide or protein building blocks. POMpeptide (POM@P) hybrid particles were synthesized as two-in-one bifunctional particles through the self-assembly of these dual inhibitors (Figure 8C) [126]. A $\beta_{15-20}$ peptides (Ac-QKLVFF- $\mathrm{NH}_{2}$ ) with a high local density can not only bind the homologous sequence in $A \beta$ peptides and disrupt their aggregation but also enhance the targeting inhibition efficiency. Moreover, congo red (CR), which is a clinically used $A \beta$ fibril-specific staining dye, was loaded into the nanospheres for real-time monitoring of the inhibition process of POM@P. Todevelop novel drugs with multiple functions against AD, Gao et al. synthesized AuNPs@POM-peptide as a novel multifunctional A $\beta$ inhibitor (Figure 8D) [127]. In this hybrid, AuNPs were utilized to carry two inhibitors (POMs and LPFFD peptides) to efficiently cross the BBB. In addition to the inhibition of $A \beta$ aggregation and the dissociation of A $\beta$ fibrils, AuNPs@POMD-peptides also decreased A $\beta$-heme peroxidase activity and $A \beta$-induced cytotoxicity via synergistic effects. Based on a similar principle, AuNRs with a high NIR absorption property were used instead of AuNPs for the hyperthermia-induced disassembly of $A \beta$ fibrils [128]. Moreover, due to the shape and size-dependent optical properties, AuNRs could also be used to sensitively detect the $A \beta$ aggregates. 


\subsubsection{Cerium Oxide Nanoparticles (CNPs)}

Owing to their rapid transformation between $\mathrm{Ce}^{4+}$ and $\mathrm{Ce}^{3+}$ at physiological $\mathrm{pH}$, $\mathrm{CeO}_{2} \mathrm{NPs}$ can act as free radical scavengers and protect cells from oxidative stress. $\mathrm{CeO}_{2}$ NPs possess powerful multienzyme activity, including superoxide oxidase, catalase and oxidase [129]. Although $\mathrm{CeO}_{2} \mathrm{NPs}$ exhibit no obvious inhibition effect on $\mathrm{A} \beta$ aggregation, it is usually utilized to eliminate over-expressed ROS produced by $\mathrm{A} \beta-\mathrm{Cu}^{2+}$ and protect against neurodegeneration $[130,131]$. To realize the targeted delivery of AD therapeutic agents, $\mathrm{Li}$ et al. designed a double delivery platform for $\mathrm{AD}$ treatment based onthe $\mathrm{H}_{2} \mathrm{O}_{2}-$ responsive release of antioxidant $\mathrm{CeO}_{2} \mathrm{NPs}$ and the metal chelator clioquinol (CQ) [132] In this study, CQ was entrapped into the phenylboronic-acid-modified MSN (MSN-BA) and glucose-coated $\mathrm{CeO}_{2}$ wasused as the gatekeeper via the formation of cyclic boronate moieties. $\mathrm{H}_{2} \mathrm{O}_{2}$ could induce the breakage of arylboronic esters, thus resulting in the release of $\mathrm{CeO}_{2} \mathrm{NPs}$ and $\mathrm{CQ}$. Finally, the two-in-one bifunctional nanoparticles effectively inhibited $A \beta$ aggregation, reduced intracellular ROS and rescued cells from $A \beta$-related toxicity. To treat $\mathrm{AD}$ in multiple pathways, Guan et al. prepared $\mathrm{CeO}_{2} \mathrm{NPs}$ with a functional $\mathrm{MnMoS}_{4}$ shell (CeNPs@MnMoS $\left.-\mathrm{n} ; n=1-5\right)$, as displayed in Figure 9A [133]. $\mathrm{MnMoS}_{4}$ could eliminate intracellular toxic $\mathrm{Cu}^{2+}$ through ion exchange. In turn, the release of $\mathrm{Mn}^{2+}$ promoted neurite outgrowth. Moreover, CeNPs@MnMoS $4-3$ with the SOD activity decreased the oxidative stress.

According to previous reports, POMs as a class of artificial proteases have the ability to hydrolyze peptides [134]. Cerium dioxide/POMs (CeONP@POMs) mixed nanoparticles were used to mimic metallopeptidase for the treatment of the neurotoxicity caused by $A \beta$ (Figure 9B) [135]. The mixed NPs with peptide hydrolysis and superoxide dismutase activity efficiently degraded $A \beta$ aggregates and decreased cellular ROS. Moreover, in addition to promoting PC12 cell proliferation and crossingthe BBB, CeONP@POMs inhibited $A \beta$-induced BV2 microglial cell activation. Kim et al. designed an extracorporeal strategy for cleansing blood $A \beta$ by using core/shell structured multifunctional magnetite/ceria nanoparticle assemblies (MCNAs) [136]. As shown in Figure 9C, the nano-assemblies were further conjugated with antifouling polyethylene glycol (PEG) and $A \beta$ antibodies for the specific capture of $A \beta$ peptides. The MNPs enabled the magnetic separation of the captured $A \beta$ peptides by applying an external magnetic field. The ceria NPs alleviated oxidative stress by scavenging the ROS generated by the immune response during the process. The blood-cleansing treatment of $5 \times \mathrm{XAD}$ transgenic mice demonstrated that the levels of $\mathrm{A} \beta$ in the blood and brain were effectively reduced and the spatial working memory deficit was rescued.

\section{4. $2 \mathrm{D}$ Nanosheets}

\subsubsection{Black Phosphorus}

As a new member of 2D layered semiconductor nanomaterials, black phosphorus (BP) has attracted broad attention because of its perfect optical and thermal properties. Moreover, BP can degrade into nontoxic phosphate and phosphite anions under physiological conditions. In 2019, Lim et al. synthesized titanium sulfonate ligand ( $\left.\mathrm{TiL}_{4}\right)$-modified BP nanosheets and BP quantum dots and reported for the first time that they could inhibit $A \beta_{1-40}$ to form fibrils by adsorbing the monomers [137]. To further improve the stability of BP, Yang et al. constructed an inhibitor (LK7)-coupled and polyethylene glycol (PEG)stabilized BP-based nano-system (PEG-LK7@BP) (Figure 10A) [138]. Besides the enhanced electrostatic and hydrophobic interactions, LK7 with a high local concentration on the $\mathrm{BP}$ surface could enhance the affinity between the A $\beta$ species and the BP. Based on the synergistic effect, PEG-LK7@BP prevented the conformational shift of $A \beta_{1-42}$ to a $\beta$-sheet structure, suppressed $A \beta_{1-42}$ aggregation and attenuated the toxicity of $A \beta_{1-42}$.

$\mathrm{BP}$ with a thickness-dependent energy bandgap from $0.3 \mathrm{eV}$ (bulk) to $2.0 \mathrm{eV}$ (monolayer) has broad absorption across the ultraviolet and entire visible light regions. BP, including the bulk material and ultrathin nanosheets, was found to be an effective photosensitizer for the generation of ${ }^{1} \mathrm{O}_{2}$ under the entire visible light region and was applied in 
the fields of catalysis and PDT [139]. Interestingly, BP QDs, BP NPs and BP NSs have been reported to possess NIR photothermal properties for PTT [140-142]. Li et al. employed BP nanosheets as the NIR-activated photosensitizer to generate ${ }^{1} \mathrm{O}_{2}$ and oxidize $\mathrm{A} \beta$ peptide in vitro and in vivo (Figure 10B) [143]. BP nanosheets were modified with 4-(6-methyl-1,3benzothiazol-2-yl) phenylamine (BTA) to increase the stability and endowed BP with A $\beta$ binding selectivity. Moreover, the BP@BTA could reduce the A $\beta$-induced cytotoxicity and show neuroprotection to the transgenic strain Caenorhabditis elegans CL2006.

A

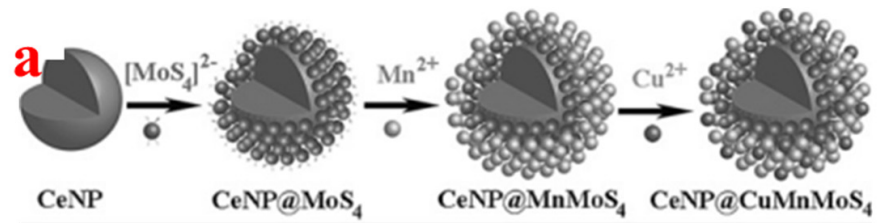

b

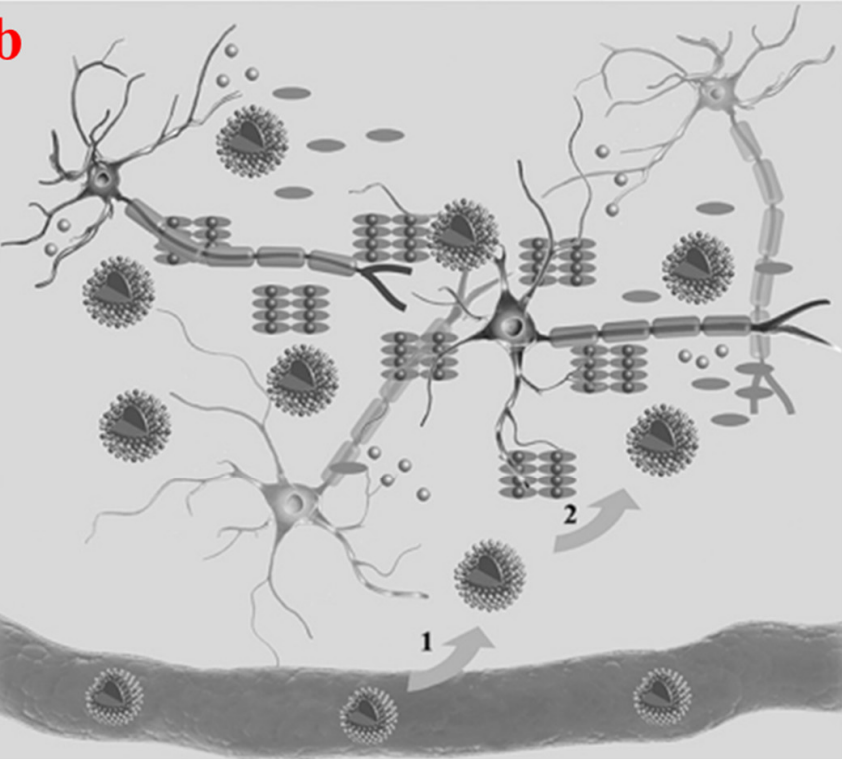

8.8
Cu Ion Induced
A 8 Aggregation

- Aß Monomer

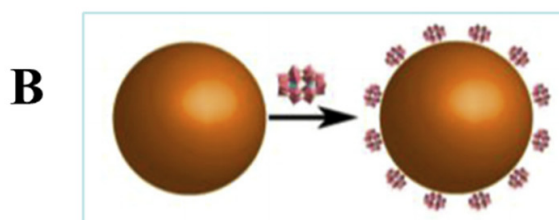

C
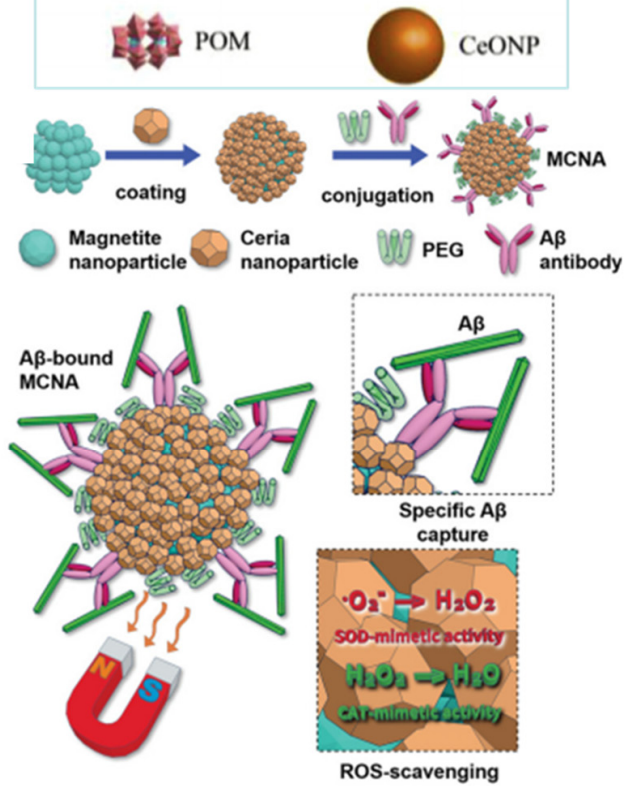

Figure 9. (A) Schematic of (a) the preparation of CeNP@MnMoS 4 -n with a $\mathrm{MnMoS}_{4}$ shell; (b) schematic interpretation of CeNP@MnMoS 4 -n in vivo. Reprinted with permission from reference [133]. Copyright 2016 Wiley-VCH. (B) Schematic drawing of the synthesis of CeONP@POMs. Reprinted with permission from reference [135]. Copyright 2016 Elsevier. (C) Schematic of the synthesis and characterization of magnetite/ceria nanoparticle assemblies. Reprinted with permission from reference [136]. Copyright 2019 Wiley-VCH.

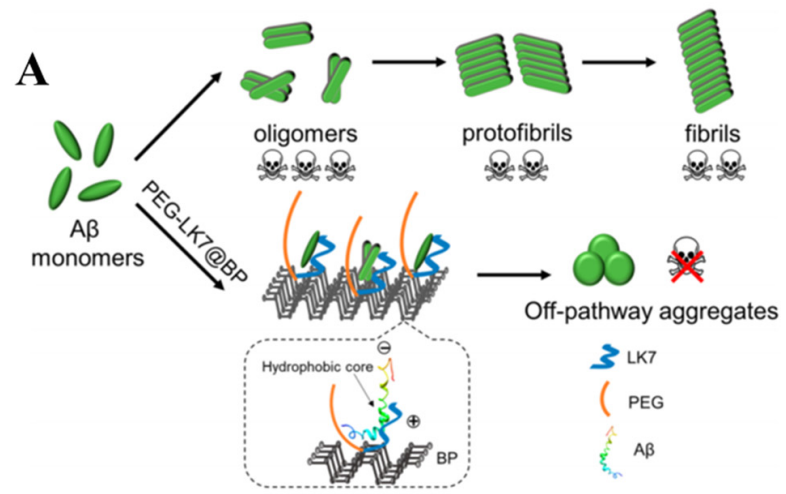

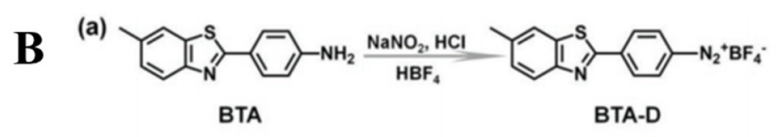
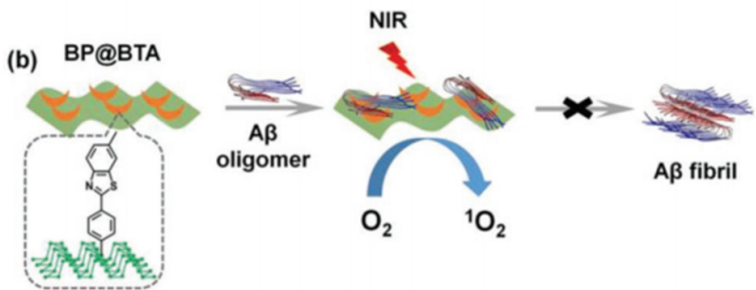

Figure 10. (A) Schematic of the $A \beta_{1-42}$ aggregation pathways influenced by PEG-LK7@BP. Reprinted with permission from reference [138]. Copyright 2020 American Chemical Society. (B) (a) Schematic illustration of the fabrication of BTA-D from BTA. (b) Schematic illustration of BP@BTA producing ${ }^{1} \mathrm{O}_{2}$ under NIR to inhibit A $\beta$ aggregation. Reprinted with permission from reference [143]. Copyright 2019 Wiley-VCH. 


\subsubsection{Transition Metal Dichalcogenides}

Transition metal dichalcogenides (TMDs) have attracted worldwide attention in the areas of nanoelectronics, optoelectronics and electrocatalysis. They are always used for drug delivery and tissue ablation. The basal plane of TMD NSs can adsorb or conjugate various aromatics (e.g., pyridine and purine) and other compounds. Mudedla et al. investigated the interaction between $\mathrm{A} \beta$ fibrils and $\mathrm{MoS}_{2}$-based materials and found that $\mathrm{MoS}_{2}$ nanotubes could inhibit the aggregation of smaller protofibrils to matured fibrils and bust the preformed fibrils [144]. Wang et al. confirmed the inhibition effect of monolayer $\mathrm{MoS}_{2}$ on the $\mathrm{A} \beta_{33-42}$ aggregation [145]. Liu et al. reported the concentration-dependent contradictory effect of AuNP-decorated $\mathrm{MoS}_{2}$ nanocomposites on $\mathrm{A} \beta_{1-40}$ aggregation [146]. As displayed in Figure 11A, a low concentration of AuNP-MoS 2 nanocomposite could act as the nuclei to accelerate the nucleus formation and fibrillation of $A \beta_{1-40}$, but a high concentration of nanocomposites could limit the structural flexibility of $A \beta_{1-40}$, leading to the inhibition of nucleus formation and aggregation.

The 2D TMDs analogous to graphene exhibit excellent properties, such as high colloidal stability in aqueous media and a high mass extinction coefficient at $800 \mathrm{~nm}$ [147]. $\mathrm{Li}$ et al. first reported that $\mathrm{WS}_{2}$ could adsorb $\mathrm{A} \beta_{1-40}$ monomers on the surface through van der Waals and electrostatic interactions, effectively inhibiting $A \beta$ aggregation and dissociating the preformed $A \beta$ fibrils via photothermal ablation upon NIR irradiation [148]. To further enhance the inhibition ability, Wang et al. prepared multifunctional $\mathrm{MoS}_{2} / \mathrm{AuNR}$ nanocomposites with high stability and good biocompatibility through electrostatic selfassembly [149]. This nanocomposite with high NIR absorption can modulate the aggregation of $A \beta$ peptides, disrupt mature fibrils under low laser power NIR irradiation and alleviate $A \beta$-induced ROS against neurotoxicity.

Artificial $A \beta$-degrading enzymes were designed for the efficient cleavage of $A \beta[150,151]$. However, the specific hydrolysis sites are always embedded inside the $\beta$-sheet structure, hindering the access and hydrolysis efficiency. Therefore, Ma et al. developed a NIR (nearIR) controllable artificial metalloprotease $\left(\mathrm{MoS}_{2}-\mathrm{Co}\right)$, combining $\mathrm{MoS}_{2}$ and a cobalt complex of 1,4,7,10-tetraazacyclododecane-1,4,7,10-tetraacetic acid (Codota) (Figure 11B) [152]. $\mathrm{MoS}_{2}-\mathrm{Co}$ can inhibit the formation of a $\beta$-sheet structure and shorten the distance between $\mathrm{A} \beta$ peptides and $\mathrm{MoS}_{2}-\mathrm{Co}$. Moreover, under NIR irradiation, $\mathrm{MoS}_{2}-\mathrm{Co}$ can produce local heat to disintegrate $A \beta$ aggregates and facilitate the hydrolysis activity of Codota toward $\mathrm{A} \beta$ peptides.

A

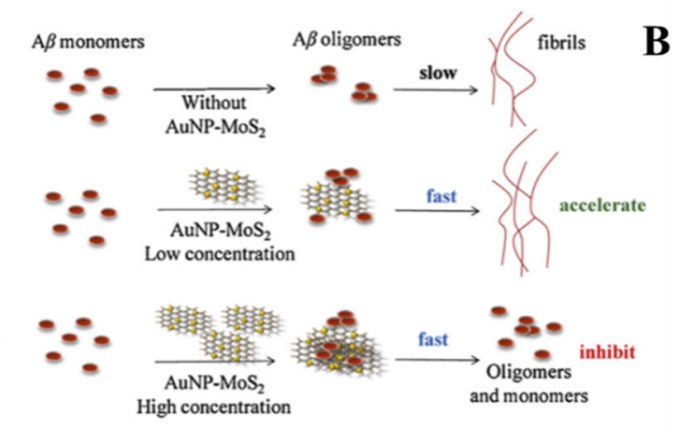

C

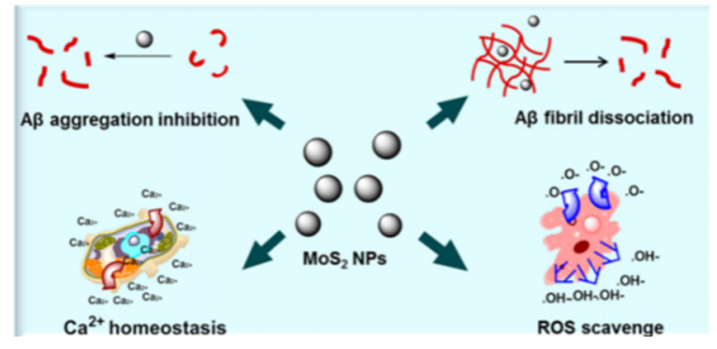

B

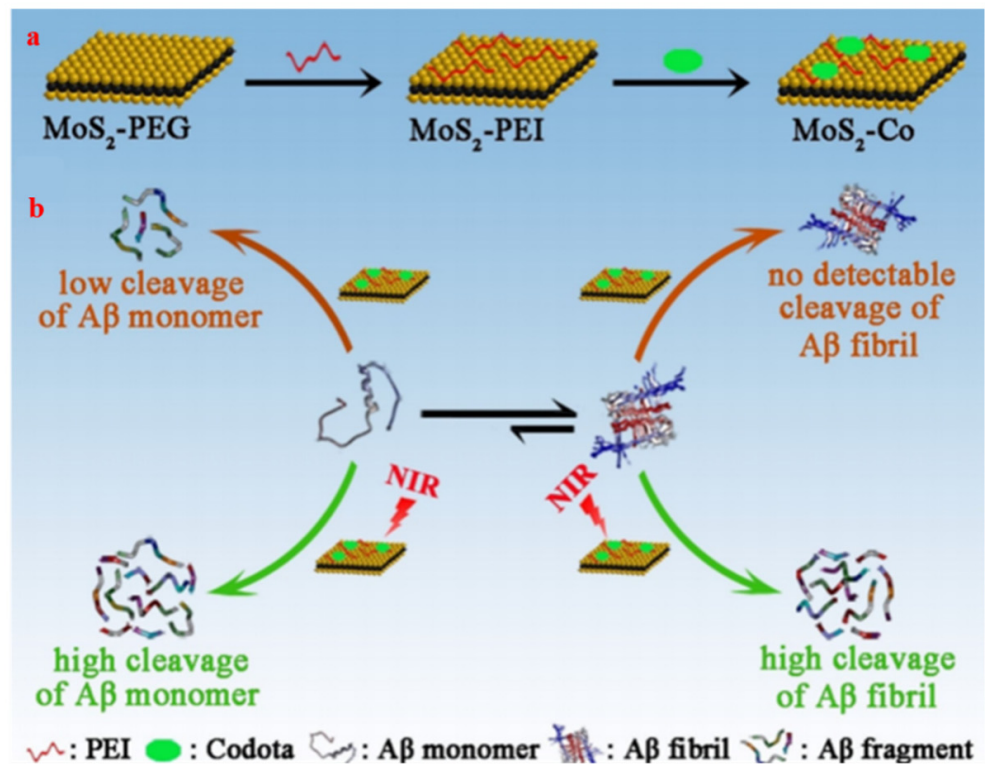

Figure 11. (A) Schematic illustration of the mechanism of the concentration-dependent effect of AuNP-MoS 2 nanocomposites on $\mathrm{A} \beta_{1-40}$ aggregation. Reprinted with permission from reference [146]. Copyright 2019 Elsvier. (B) Schematic illustration 
of the synthesis route of $\mathrm{MoS}_{2}$-Co and hydrolysis enhanced by $\mathrm{MoS}_{2}$-Co in the presence of an NIR laser. (a) Synthesis route of $\mathrm{MoS}_{2}$-Co. (b) In the presence of NIR laser, $\mathrm{MoS}_{2}$-Co not only improves the hydrolytic activity toward Ab monomers (left side) but also enhances the hydrolytic capacity toward Ab fibrils (rightside). Reprinted with permission from reference [152]. Copyright 2019 Wiley-VCH. (C) Schematic illustration of $\mathrm{MoS}_{2}$ NPs as multifunctional inhibitors against AD. Reprinted with permission from reference [153]. Copyright 2017 American Chemical Society.

$\mathrm{MoS}_{2}$ NPs are also drawing more and more interest as self-lubricating coatings and in biochemical applications. Han et al. prepared spherical polyvinylpyrrolidonefunctionalized $\mathrm{MoS}_{2}$ NPs with an average diameter of $100 \mathrm{~nm}$ using a pulsed laser ablation method and found that they show multifunctional effects on $A \beta_{1-42}$ aggregation (Figure 11C) [153]. $\mathrm{MoS}_{2}$ NPs could adsorb $A \beta_{1-42}$ monomers or oligomers on the surface based on the interaction between $M_{0} S_{2}$ NPs and the hydrophobic region of $A \beta_{1-42}$. This delays the nucleation process, inhibits $A \beta_{1-42}$ aggregation and destabilizes the preformed fibrils. As a result, the calcium channel induced by the incorporation of $A \beta_{1-42}$ oligomers into neuronal cell membranes was blocked to ensure calcium homeostasis and protect neuronal cells. Moreover, $\mathrm{MoS}_{2}$ NPs could reduce the intracellular ROS $(\cdot \mathrm{OH})$ level induced by $\mathrm{A} \beta_{1-42}$.

\subsubsection{Graphitic Carbon Nitride}

Unlike bulk $\mathrm{g}-\mathrm{C}_{3} \mathrm{~N}_{4}$, the $2 \mathrm{D}$ ultrathin $\mathrm{g}-\mathrm{C}_{3} \mathrm{~N}_{4}$ nanosheet is the most stable allotrope of carbon nitride under ambient conditions. It has excellent properties of good biocompatibility, high surface-area-to-volume ratio and nontoxicity and was employed in bioimaging, drug delivery and cancer diagnosis.

A g- $\mathrm{C}_{3} \mathrm{~N}_{4}$ nanosheet, with a narrow band gap of $2.7 \mathrm{eV}$, can act as a stable photocatalyst for water splitting and the degradation of organic pollutants. Chung et al. applied photoactive $g-\mathrm{C}_{3} \mathrm{~N}_{4}$ for the light-induced suppression of $\mathrm{A} \beta$ aggregation and toxicity [154]. As shown in Figure $12 \mathrm{~A}$, the photosensitized $\mathrm{g}-\mathrm{C}_{3} \mathrm{~N}_{4}$ generated oxidative ROS through photoinduced electron transfer under visible-light illumination, which further oxidized $A \beta$ peptides, preventing the aggregation of $A \beta$ monomers. However, $g-C_{3} N_{4}$ had no obvious effect on $\mathrm{A} \beta$ aggregation under dark conditions. Moreover, doping transition metal ions could promote ROS generation and enhance their inhibition efficiency. To enhance the photodegradation efficiency, Wang et al. used GO/g- $\mathrm{C}_{3} \mathrm{~N}_{4}$ as the photocatalyst for irreversible disassembly of $\mathrm{A} \beta_{33-42}$ aggregate into nontoxic monomers under UV (Figure 12B) [155]. In this nanocomposite, $\mathrm{GO}$ acts as an $\mathrm{A} \beta$ collector due to its high surface area and abundant functional groups. $\mathrm{g}-\mathrm{C}_{3} \mathrm{~N}_{4}$ was also decorated with AuNPs to separate photoexcited electron-hole pairs [156].

Based on its strong adsorption capacity for metal ions, Li et al. reported that a g- $\mathrm{C}_{3} \mathrm{~N}_{4}$ nanosheet could act as the chelator to block $\mathrm{Cu}^{2+}$-induced $\mathrm{A} \beta$ aggregation, disaggregate the preformed $\mathrm{A} \beta-\mathrm{Cu}^{2+}$ aggregates, reduce the ROS level induced by $\mathrm{A} \beta-\mathrm{Cu}{ }^{2+}$ and block $A \beta$-mediated toxicity [157]. At the same time, they also found that platinum(II)coordinated g- $\mathrm{C}_{3} \mathrm{~N}_{4}\left(\mathrm{~g}-\mathrm{C}_{3} \mathrm{~N}_{4} @ \mathrm{Pt}\right)$ can covalently bind to $\mathrm{A} \beta$ monomers and oxygenate $\mathrm{A} \beta$ monomers and oligomers upon visible light irradiation, thus inhibiting the aggregation and toxicity of $A \beta$ [158]. Furthermore, they found that the accumulation of oxygenated $A \beta$ can inhibit the aggregation of native $A \beta$ peptides.

For targeted therapy, Gong et al. developed an intelligent $A \beta$ nanocaptor by anchoring $\mathrm{C}_{3} \mathrm{~N}_{4}$ nanodots to $\mathrm{Fe}_{3} \mathrm{O}_{4} @ \mathrm{MSN}$ and modifying them with benzothiazole aniline (BTA) (B$\mathrm{FeCN}$ ), as shown in Figure $12 \mathrm{C}$ [159]. In this nanocomposite, $\mathrm{C}_{3} \mathrm{~N}_{4}$ nanodots could capture $\mathrm{Cu}^{2+}$, subsequently blocking the formation of the $\mathrm{A} \beta-\mathrm{Cu}^{2+}$ complex and diminishing $\mathrm{A} \beta$ aggregation. $\mathrm{Fe}_{3} \mathrm{O}_{4}$ could cause local low-temperature hyperthermia to enhance the $\mathrm{BBB}$ permeability and dissolute the A $\beta$ plaques. In addition, BTA endowed the nanocaptor with aspecific targeting ability and fluorescent imaging property for monitoring $\mathrm{A} \beta$ aggregates. 


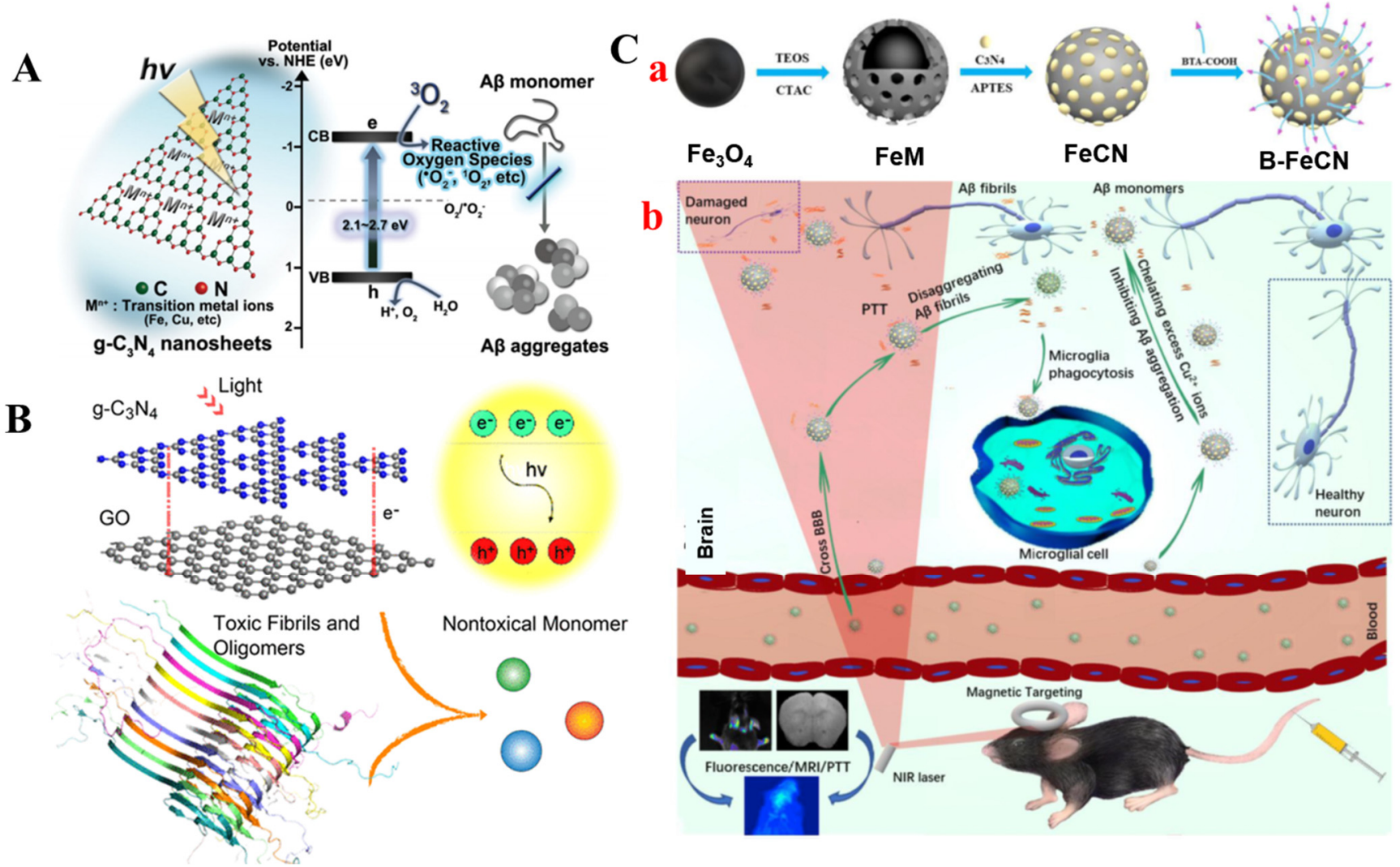

Figure 12. (A) Schematic illustration of $g-C_{3} N_{4}$ NSs as an $A \beta$ aggregation inhibitor. Reprinted with permission from reference [154]. Copyright 2016 Wiley-VCH. (B) Schematic illustration of the degradation of A $\beta$ aggregates using GO/g$\mathrm{C}_{3} \mathrm{~N}_{4}$ under light irradiation. Reprinted with permission from reference [155]. Copyright 2019 American Chemical Society. (C) (a) Schematic illustration of the preparation of B-FeCN nanocaptors. (b) Schematic illustration of the B-FeCN nanosystem as a multifunctional nanocaptor to inhibit $A \beta$ aggregation for the magnetic targeting phototherapy of $A D$ treatment. Reprinted with permission from reference [159]. Copyright 2021 Elsevier.

\subsection{Metal-Organic Frameworks}

As increasingly popular crystalline porous materials, metal-organic frameworks (MOFs) are built from metal nodes and organic linkers. Benefitting from the control of chemical functionality, pore size and crystal morphology, they have been used in many fields, including catalysis, gas storage, drug delivery and biosensing. Owing to the exposed metal sites and porphyrin linkers with aromatic rings, porphyrinic MOFs are particularly attractive for biomedical research. Porphyrinic MOF PCN-224 was prepared for the NIR-induced suppression of $A \beta$ peptide aggregation (Figure 13A) [160]. Besides good biocompatibility and excellent stability, $\mathrm{PCN}-224$ showed singlet oxygen generation capability in the NIR window because of the high density of the photosensitizer molecule TCPP in the framework and the easy diffusion of $\mathrm{O}_{2}$ through the porous structure. The results showed that the photoactivated PCN-224 could effectively inhibit the aggregation of $A \beta_{1-42}$ into a high-order $\beta$-sheet-rich structure and rescue the cytotoxicity of $A \beta_{1-42}$. According to the previous report, the nitrogen atoms in porphyrin from porphyrinic MOF possess a high binding affinity to $\mathrm{Cu}^{2+}$ ions [161]. Inspired by these findings, Yu et al. utilized porphyrinic $\mathrm{MOF}$ as a $\mathrm{Cu}^{2+}$-chelator and photooxidation agent for inhibiting $\mathrm{A} \beta$ peptide aggregation (Figure 13B) [162]. To further enhance the selectivity and photooxidation efficiency, MOFs were modified with the A $\beta$-targeting peptide LPFFD. As one sub-class of the MOF family, Prussian blue (PB) has numerous applications, including electrocatalysis, bioimaging and biosensing. According to the previous reports, it can act as a nanozyme to scavenge ROS and trap metal ions in its lattice cavities. Recently, Kowalczyk et al. studied the dual effects of $\mathrm{PB}$ on inhibiting $\mathrm{A} \beta_{1-40}$ aggregation and chelating $\mathrm{Cu}^{2+}$ [163]. They found that PB- 
could accelerate the nucleation of $A \beta_{1-40}$ and facilitate the formation of $A \beta_{1-40}$ amorphous aggregates instead of $\beta$-sheet fibrils.

$\mathbf{A}$

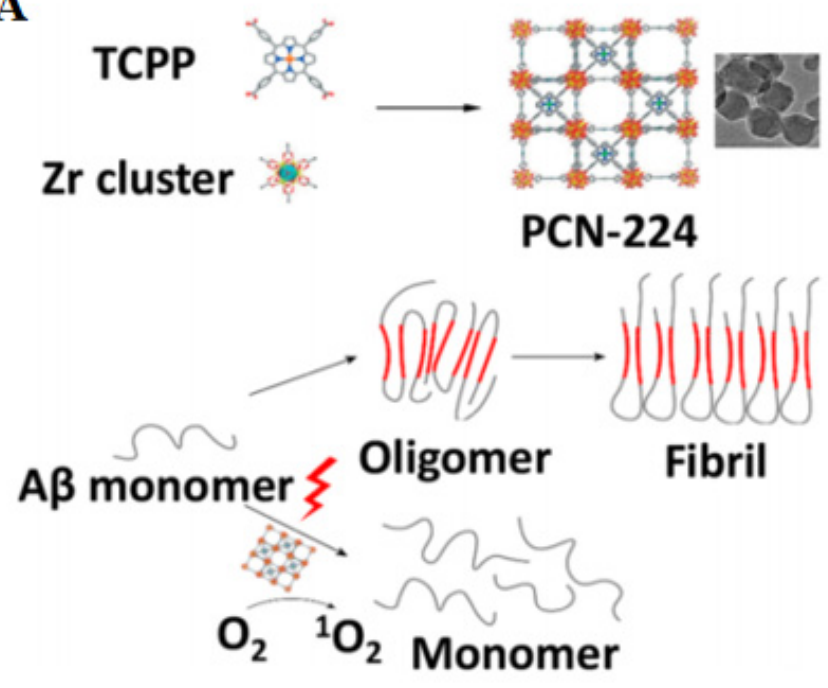

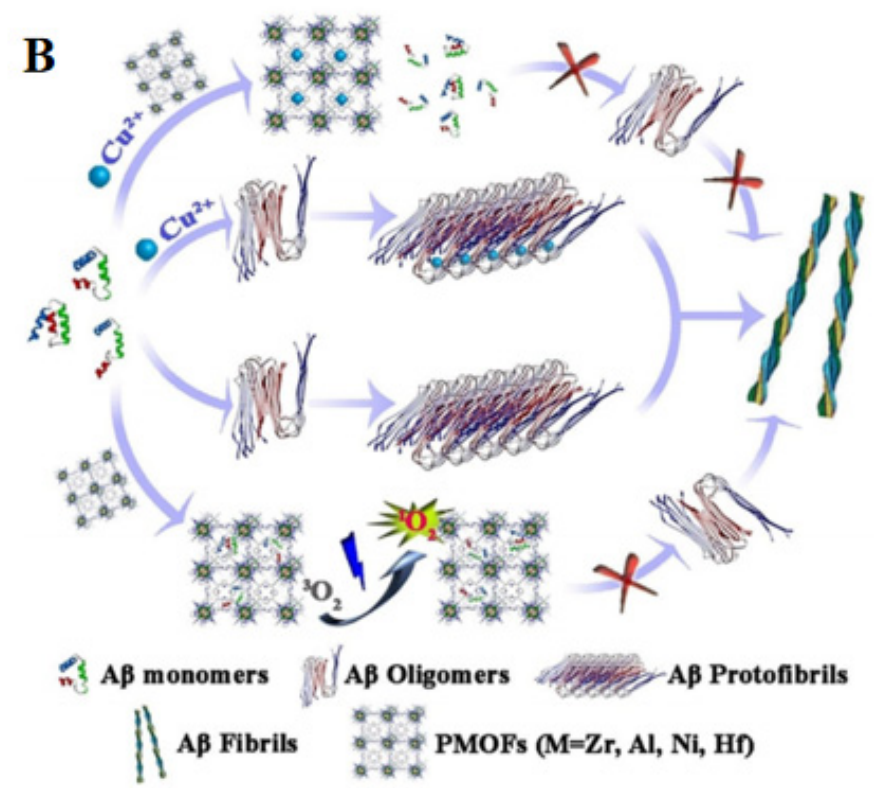

Figure 13. (A) Schematic diagram of the photo-inhibition of $A \beta_{1-42}$ aggregation using PCN-224 nanoparticles. Reprinted with permission from reference [160]. Copyright 2018 American Chemical Society. (B) Schematic illustration of the possible mechanism of inhibition effect of porphyrinic MOFs on the amyloid fibrillation process. Reprinted with permission from reference [162]. Copyright 2019 Wiley-VCH.

\subsection{Semiconductor Quantum Dots}

Unlike traditional fluorescent organic dyes, semiconductor quantum dots (QDs) have shown excellent optical properties, including size-dependent emission wavelengths, high resistance to photobleaching and multicolor fluorescence emission with a single excitation. Thus, QDs are widely utilized in various applications, such as drug delivery, fluorescent biosensing and tissue imaging. Furthermore, QDs have been utilized as promising candidates against amyloidosis formonitoring and inhibiting $A \beta$ aggregation [164].

QDs (NAC-QDs) capped with N-acetyl-L-cysteine were reported to quench both the nucleation and elongation processes resulting from the intermolecular attractive interactions, such as hydrogen bonding between NAC-QDs and amyloid fibrils and the blockage of the active elongation sites on the A $\beta$ fibrils [165]. Furthermore, NAC-QDs have a neuro-protective ability against the cytotoxicity induced by $\mathrm{A} \beta$ peptides on human neuroblastoma SH-SY5Y cells [166]. Dihydrolipoic acid(DHLA)-capped CdSe/ZnS QDs also reduced the fibrillation process [167].

\subsection{Self-Assembled Nanomaterials}

\subsubsection{Liposomes}

Liposomes have been used in drug delivery, because of their non-toxic, high drugloading capacity and their ease of preparation and modification. In 1999, Maria et al. studied the structure of $A \beta_{25-35}$ and explored its association with different phospholipid membrane vesicles [168]. It was found that three kinds of negatively charged vesicles could accelerate the aggregation of $A \beta_{25-35}$ based on the electrostatic interaction, while vesicles formed by the zwitterionic phospholipid could slow down the aggregation of $A \beta_{25-35}$. Neutral liposomes increase the time of $A \beta$ aggregation in a concentration-dependent manner [169]. The effect of NLs with different sizes on the A $\beta$ aggregation was also investigated by Terakawa and co-workers [170]. Liposomes with smaller sizes $(<50 \mathrm{~nm})$ promoted the nucleation and yet those with larger sizes decreased the amount of fibrils and had no influence on the lag time of fibrillation. Shimanouchi et al. reported that $\mathrm{Cu}^{2+}$ 
affected the fibrillar aggregates formed on the surface of oxidized and negatively charged liposomes, such as the oxidatively damaged neuronal cell membranes [171]. Thus, anionic liposomes can result in the formation of spherulitic $A \beta$ aggregates.

Various methods have been proposed by incorporating or modifying the liposomes with different molecules, peptides or antibodies for targeting the $A \beta$ aggregates and plaques [172-174]. Nanoliposomes containing anionic phosphatidic acid (PA) or cardiolipin (CL) can bind with all formats of $A \beta_{1-42}$ aggregates with high affinity and thus reduce $A \beta$-induced toxicity $[175,176]$. Mourtas et al. found that the planarity of curcumin on the liposome has an important influence on the affinity toward $A \beta$ aggregates, which is dependent upon the conjugation method [177]. Moreover, Taylor et al. demonstrated that curcumin-modified liposome synthesized using click chemistry was the most effective in the inhibition of $A \beta$ aggregation [178]. Canovi et al. decorated NLs with an anti$\mathrm{A} \beta$ monoclonal antibody ( $\mathrm{A}-\mathrm{MAb})$ to achieve a high affinity toward $\mathrm{A} \beta$ monomers and fibrils [179]. Moreover, the multifunctional conjugation of NLs containing PA, CL, curcumin with apolipoprotein $\mathrm{E}$ or the anti-transferrin receptor antibody can facilitate the crossing of the BBB and enhance the uptake in the brain capillary cells without the sacrifice of $A \beta$ targeting [180-182]. For instance, liposomes bi-functionalized with PA and an ApoE-derived peptide destabilized the preformed $A \beta_{1-42}$ aggregates under the synergic action and could cross the BBB in vitroandin vivo [183,184].

\subsubsection{Polymer Nanoparticles}

Celia et al. demonstrated that copolymeric NiPAM:BAM nanoparticles increased the nucleation time of $A \beta$ fibrillation, but the elongation step remained largely unaffected, which isdependent uponthe concentrationand hydrophobicity [185]. Through studying the effect of cationic amino-modified PS NPs, they indicated that there is a balance between two different pathways: fibrillation of the free monomer in solution and the nucleation and fibrillation accelerated at the particle surface, which can be determined by the ratio between the peptide and NPs concentration (Figure 14A) [186]. Biopolymeric chitosan-based NPs were also reported to show the ability to inhibit $A \beta$ aggregation and disintegrate the preformed fibrils [187].

The positively charged fluorescent conjugated polymer NPs (CPNPs) were prepared to inhibit $\mathrm{A} \beta_{1-40}$ peptide fibrillation (Figure 14B) [188]. Moreover, CPNPs with excellent photophysical properties provided fluorescence signals for probing the interaction with $A \beta$ peptides. They found that CPNPs could not only inhibit the aggregation of $A \beta$ but also bind with the terminal of seed fibrils, preventing further fibrillation. A photosensitive polymer nanodot was designed by modifying it with a photosensitizer for efficient suppression of $A \beta$ aggregation [189]. Dou et al. produced fluorogenic "nanogrenades" based on supermolecular assembly between organic dyes and conjugated polymers [190]. The quenched fluorescence of dyes in the nanogrenades was recovered after binding with hydrophobic $A \beta$ fibril plaques. The conjugated polymers in the nanogrenades could generate ROS to destruct the $A \beta$ plaques usingwhite light irradiation.

NPs assembled using conjugated polymers can also be applied to construct stimuliresponsive drug delivery systems. Recently, to ensure targeting and selectivity, Lai et al. designed versatile NPs with a high A $\beta$-binding affinity, stimuli-responsive drug release and a photothermal degradation ability for the dissolution of $A \beta$ [191]. As shown in Figure 14C, the NPs were composed of an NIR-absorbing conjugated polymer-formed photothermal core and a thermal-responsive polymer-formed shell as NIR-stimuli gatekeeper. Inhibitor curcumin was loaded into the NPs andthe peptide LPFFDwas modified on the surface of NPs for targeting A $\beta$. Upon NIR laser irradiation, local heat generated by the core could not only trigger the release of encapsulated curcumin to inhibit the aggregation of $A \beta$ but also effectively dissociate the $A \beta$ deposits. Moreover, the $A \beta$ fibrillation and disassembly could be real-time monitored due to the intrinsic polarity-dependent fluorescence of curcumin. 

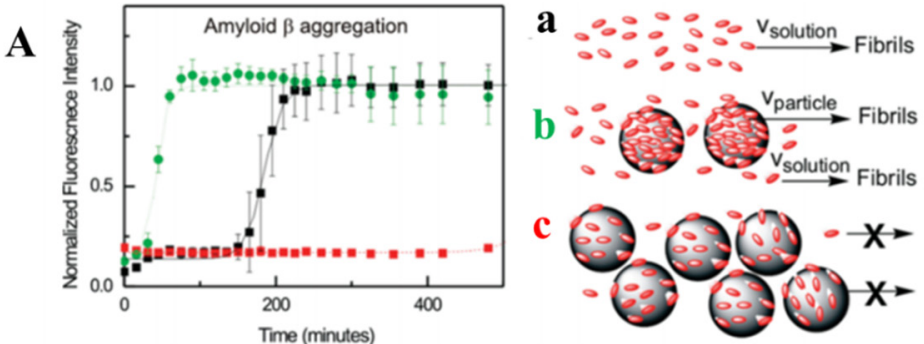

\section{C}

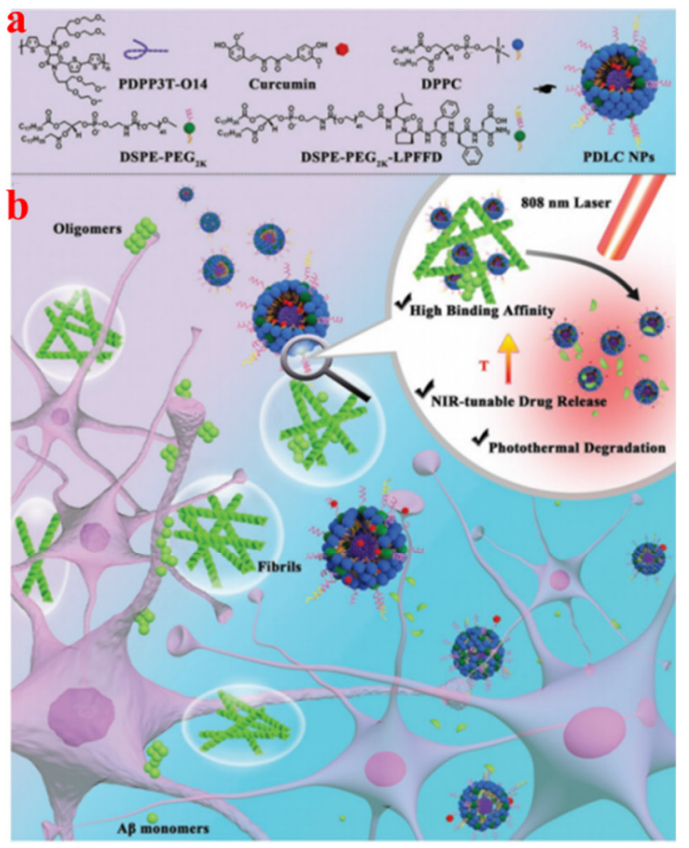

Figure 14. (A) Schematic of the dual effect of amino-modified polystyrene nanoparticles on A $\beta$ fibrillation. (a) The fibrillation of $A \beta_{1-40}$ in the absence of nanoparticles shows the typical nucleation-elongation profile. (b) The fibrillation process is accelerated (shorter lag phase) by nanoparticles at low particle concentration (c) At high particle concentration, the fibrillation process is retarded (longer lag phase). Reprinted with permission from reference [186]. Copyright 2010 American Chemical Society. (B) Schematic diagram of the procedures for CPNPs fabrication and A $\beta_{1-40}$ fibril inhibition with CPNPs. Reprinted with permission from reference [188]. Copyright 2019 American Chemical Society. (C) Schematic illustration of PDLC NPs for chemo-photothermal treatment for A $\beta$ aggregation. (a) Chemical structures and the synthesis of PDLC NPs. (b) Schematic illustration of PDLC NPs-mediated chem-photothermal treatment by combining NIR light-tunable drug release and photodegradation of amyloid $\beta$. Reprinted with permission from reference [191]. Copyright 2019 American Chemical Society.

Dopamine can self-assemble into melanin-like poly(dopamine) (PDA) NPs under alkaline conditions with oxygen as the oxidant. PDA NPs with functional groups (i.e., catechol and amine) on the surface can interact with peptides and proteins. Our group was the first to find out that PDA NPs could prevent the formation of $A \beta$ fibrils via the hydrogen bonding and aromatic interactions between A $\beta$ and PDA NPs [192]. Moreover, eumelanin-like particles and pheomelanin-like particles could also perturb the $A \beta_{1-42}$ aggregation and remodel the matured $A \beta_{1-42}$ fibers [192].

Inspired by the self-assembly of biomolecules into complicated functionalized units in cells and nature, researchers put efforts into the self-assembly of different molecules from natural small molecules to peptides, even to proteins. Among those self-assembly blocks, low-molecular-weight peptides have attracted significantattention due to their flexible sequences and biodegradability. Recently, Liu et al. proposed a peptide-based porphyrin supramolecular self-assembly (PKNPs) for target-driving the selective photooxygenation of A $\beta$ [193]. Porphyrin-peptide conjugate (PP-KLVFF) can be self-assembled into PKNPs via hydrophobic interactions and $\pi-\pi$ stacking interactions, resulting in the suppression of the intrinsic fluorescence emission, the generation of ROS by free porphyrin and the enhancement of photo-to-thermal conversion ability. The photothermal effect facilitated the crossingof the BBB and then $A \beta$ selectively initiated the disassembly of PKNPs into free porphyrin to produce ROS under light irradiation and thus oxygenated the $A \beta$.

\subsection{Others}

In the PDT, visible (or UV) light-activated photosensitizers are always confronted with the problem that the penetration depth of UV-visible light in biological tissues is limited. To solve this problem, the upconversion nanoparticles (UCNPs) with the ability to convert 
NIR light into short-wavelength light are attractive for therapeutic applications. As shown in Figure 15A, Kuk et al. proposed a NIR-light-responsive strategy for the suppression of $A \beta$ aggregation [194]. In this work, rattle-structured organosilica-shell-coated, $\mathrm{Yb} / \mathrm{Er}$ co-doped $\mathrm{NaYF}_{4} \mathrm{NPs}_{\mathrm{s}}$ were synthesized with an interior cavity to encapsulate numerous rose bengal (RB) molecules with a high loading efficiency and no self-aggregation. Since the absorption of RB partially overlapped with the green emission of UCNPs, visiblelight-absorbing RB was activated by UCNPs under $980 \mathrm{~nm}$ NIR light, through the highly efficient energy transfer to generate oxidative ${ }^{1} \mathrm{O}_{2}$, oxidize peptides and preclude the $\mathrm{A} \beta$ fibrillogenesis. However, in dark conditions, a delayed elongation rate but an unaltered amount of total $A \beta$ aggregate was recorded, which wasascribed to the intrinsic inhibition ability of the positively charged UCNPs. Moreover, the biocompatible UCNPs also showed effective suppression of the $A \beta$-induced cytotoxicity under NIR light.

Polyphenol compounds can inhibit $A \beta$ aggregation and decrease the generation of ROS. However, excess metal ions in $\mathrm{A} \beta$ plaque can bind with them, resulting in a decreasein efficacy. Ma et al. proposed a NIR-responsive UCNPs-caged system to sequentially release drugs by regulating them using an NIR laser [195]. As shown in Figure 15B, the metal chelator CQ and polyphenol curcumin were conjugated on the surface of UCNPs using two NIR-sensitive linkers. After being irradiated by a low-power laser, CQ was released to remove free metal ions. Then, curcumin was released to clear superfluous ROS by increasing the intensity of the laser, leading to enhanced treatment efficacy.

Chiral amino acids or peptides conjugated on the NPs can endow NPs with chiral properties, which have aroused interest in the applicability of chiral NPs in different fields. Recently, Zhang et al. found that D-type penicillamine (D-Pen)-modified $\mathrm{Fe}_{\mathrm{x}} \mathrm{Cu}_{\mathrm{y}} \mathrm{Se}$ nanoparticles (NPs) showed higher efficiency in the inhibition of $\mathrm{A} \beta_{1-42}$-monomer aggregation and enhancement of the dissociation of $A \beta_{1-42}$ fibrils under NIR light irradiation in 10 min (Figure 15C) [196].

Sulfur nanomaterials have the excellent ability to remove $\mathrm{Cu}^{2+}$ ions and radicals. Sun et al. synthesized three RVG-peptide-modified sulfur NPs (SNPs) with different morphologies and study their influence on the aggregation of $\mathrm{A} \beta-\mathrm{Cu}^{2+}$ complexes and corresponding neurotoxicity [197]. They found that the sphere-like SNPs exhibited the most effective inhibition activity owing to the small size, thus reducing the $\mathrm{A} \beta-\mathrm{Cu}^{2+}$-induced ROS and increasingthe cell viability (Figure 15D). 
A

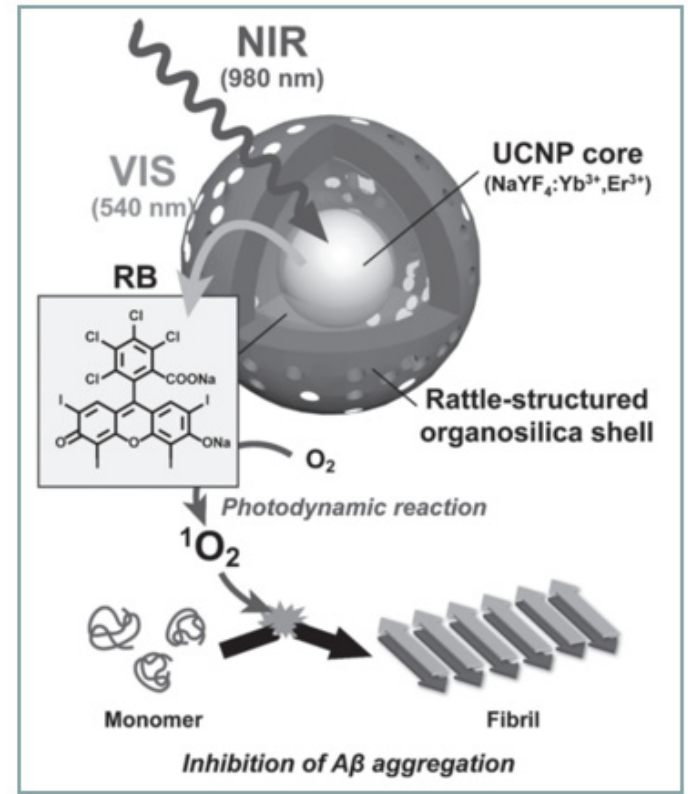

B

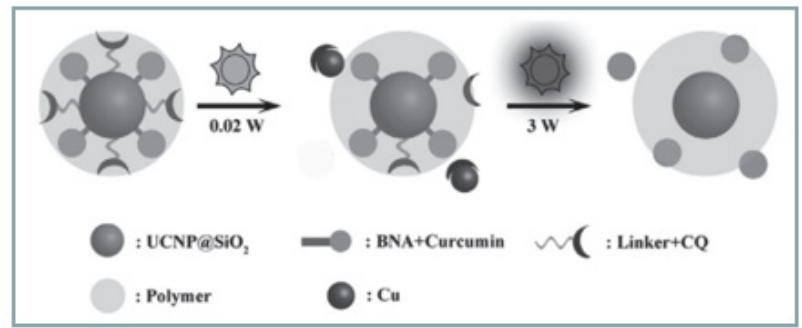

C

D
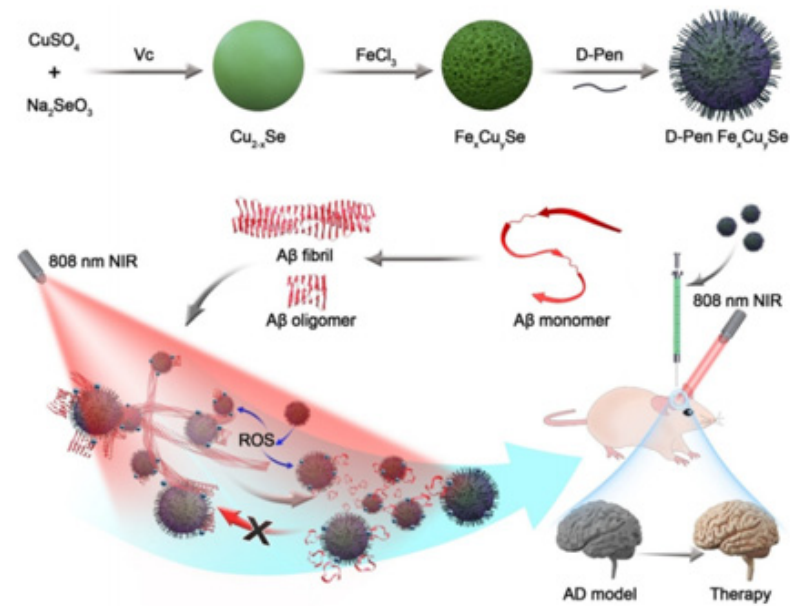

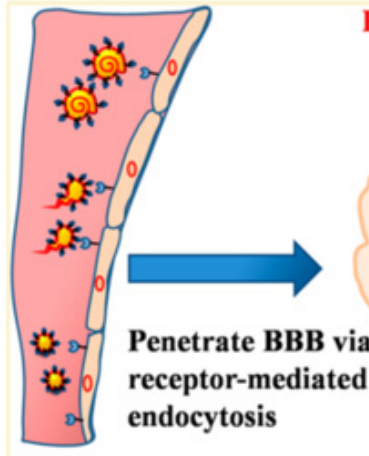

Blood
Extracellular $\mathrm{A} \beta$ plaque and $\mathrm{Cu}^{2+}$

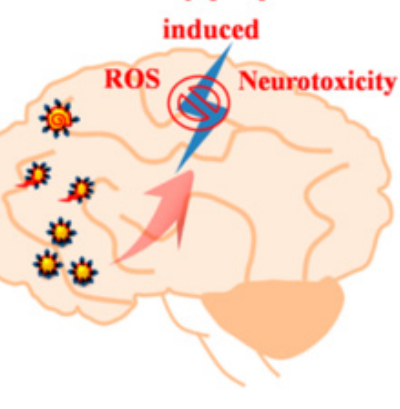

Brain

Figure 15. (A) Schematic of $A \beta$ aggregation inhibition by NIR-responsive rattle-structured UCNPs. Reprinted with permission from reference [194]. Copyright 2017 Wiley-VCH. (B) Illustration of agents that are sequentially released during a process based on 980 nm NIR light-triggered UCNP@SiO ${ }_{2} @ C u r / C Q$. Reprinted with permission from reference [195]. Copyright 2017 Wiley-VCH. (C) Schematic of the synthesis of Pen modified $\mathrm{Fe}_{\mathrm{x}} \mathrm{Cu}_{\mathrm{y}}$ Se and illustration of the inhibition and disassembly effects of D-Pen-modified $\mathrm{Fe}_{\mathrm{x}} \mathrm{Cu}_{\mathrm{y}} \mathrm{Se}$ on $\mathrm{A} \beta_{1-42}$ aggregation and the mitigation of potential neurotoxicity in an AD mice model. Reprinted with permission from reference [196]. Copyright 2018 Wiley-VCH. (D) Schematic of the inhibition $A \beta$ aggregation by sulfur NPs. Reprinted with permission from reference [197]. Copyright 2018 American Chemical Society.

\section{Conclusions}

In this review, we give a brief overview of recent achievements of nanomaterial-based modulation of $A \beta$ aggregation. Nanomaterials for the treatment of AD play multiple roles. First, most nanomaterials can directly interact with $A \beta$ peptidesto accelerate or slow the aggregation. Second, nanomaterials can act as nano-carriers for loading of various drugs to allow themto cross the BBB and improve the local concentration of drugs. Third, nanomaterials with photosensitive properties can influence the format of A $\beta$ through PTT or PDT. Although the development of nanomaterials opens a brandnew chapter in the treatment of $\mathrm{AD}$, more efforts are still urgently needed and more novel nanomaterials should be explored and investigated. For example, MXene, which is a novel type of 2Dnanosheet that is mainly composed of early transition metal carbides, has attracted a great deal of attention in energy evolution and nanomedicine [198]. Moreover, metal ions on the MXene surface may interact with $\mathrm{A} \beta$ peptides or aggregates. Although there are increasing studies focusing on the interactions between nanomaterials and $A \beta$, a deep and comprehensive understanding of its nature and application is still necessary. 
Author Contributions: Conceptualization, Y.H. and L.L.; writing-original draft preparation, Y.H. and Y.C.; writing-review and editing, J.W.; project administration, L.L.; funding acquisition, J.W. All authors have read and agreed to the published version of the manuscript.

Funding: This research was funded by the National Natural Science Foundation of China (22076221) and the Program for Innovative Research Team of Science and Technology in the University of Henan Province (21IRTSTHN005).

Conflicts of Interest: The authors declare no conflict of interest.

\section{References}

1. Tao, Y.X.; Conn, P.M. Pharmacoperones as Novel Therapeutics for Diverse Protein Conformational Diseases. Physiol. Rev. 2018, 98, 697-725. [CrossRef]

2. Jarosz, D.F.; Khurana, V. Specification of Physiologic and Disease States by Distinct Proteins and Protein Conformations. Cell 2017, 171, 1001-1014. [CrossRef]

3. Klementieva, O.; Willen, K.; Martinsson, I.; Israelsson, B.; Engdahl, A.; Cladera, J.; Uvdal, P.; Gouras, G.K. Pre-Plaque Conformational Changes in Alzheimer's Disease-Linked A $\beta$ and App. Nat. Commun. 2017, 8, 14726. [CrossRef]

4. Blennow, K.; de Leon, M.J.; Zetterberg, H. Alzheimer's Disease. Lancet 2006, 368, 387-403. [CrossRef]

5. Kiernan, M.C.; Vucic, S.; Cheah, B.C.; Turner, M.R.; Eisen, A.; Hardiman, O.; Burrell, J.R.; Zoing, M.C. Amyotrophic Lateral Sclerosis. Lancet 2011, 377, 942-955. [CrossRef]

6. Yepes, M. The Plasminogen Activating System in the Pathogenesis of Alzheimer's Disease. Neural Regen. Res. 2021, 16, 1973-1977. [CrossRef]

7. Caselli, R.J.; Knopman, D.S.; Bu, G. An Agnostic Reevaluation of the Amyloid Cascade Hypothesis of Alzheimer's Disease Pathogenesis: The Role of App Homeostasis. Alzheimers Dement. 2020, 16, 1582-1590. [CrossRef] [PubMed]

8. Canevelli, M.; Bruno, G.; Cesari, M. The Sterile Controversy on the Amyloid Cascade Hypothesis. Neurosci. Biobehav. Rev. 2017, 83, 472-473. [CrossRef]

9. Hu, W.; Zhang, X.; Tung, Y.C.; Xie, S.; Liu, F.; Iqbal, K. Hyperphosphorylation Determines Both the Spread and the Morphology of Tau Pathology. Alzheimers Dement. 2016, 12, 1066-1077. [CrossRef]

10. Styr, B.; Slutsky, I. Imbalance between Firing Homeostasis and Synaptic Plasticity Drives Early-Phase Alzheimer's Disease. Nat. Neurosci. 2018, 21, 463-473. [CrossRef]

11. Breijyeh, Z.; Karaman, R. Comprehensive Review on Alzheimer's Disease: Causes and Treatment. Molecules 2020, $25,5789$. [CrossRef]

12. Flammang, B.; Pardossi-Piquard, R.; Sevalle, J.; Debayle, D.; Dabert-Gay, A.S.; Thevenet, A.; Lauritzen, I.; Checler, F. Evidence That the Amyloid-B Protein Precursor Intracellular Domain, Aicd, Derives from B-Secretase-Generated C-Terminal Fragment. J. Alzheimers Dis. 2012, 30, 145-153. [CrossRef] [PubMed]

13. Checler, F. Processing of the B-Amyloid Precursor Protein and Its Regulation in Alzheimer's Disease. J. Neurochem. 1995, 65, 1431-1444. [CrossRef] [PubMed]

14. Iwatsubo, T.; Odaka, A.; Suzuki, N.; Mizusawa, H.; Nukina, N.; Ihara, Y. Visualization of A $\beta 42(43)$ and A $\beta 40$ in Senile Plaques with End-Specific A $\beta$ Monoclonals: Evidence That an Initially Deposited Species Is A $\beta 42(43)$. Neuron 1994, 13, 45-53. [CrossRef]

15. Haass, C.; Selkoe, D.J. Soluble Protein Oligomers in Neurodegeneration: Lessons from the Alzheimer's Amyloid B-Peptide. Nat. Rev. Mol. Cell Biol. 2007, 8, 101-112. [CrossRef]

16. Yang, J.; Zhang, X.; Yuan, P.; Yang, J.; Xu, Y.; Grutzendler, J.; Shao, Y.; Moore, A.; Ran, C. Oxalate-Curcumin-Based Probe for Micro- and Macroimaging of Reactive Oxygen Species in Alzheimer's Disease. Proc. Natl. Acad. Sci. USA 2017, 114, 12384-12389. [CrossRef] [PubMed]

17. Yan, L.M.; Velkova, A.; Tatarek-Nossol, M.; Andreetto, E.; Kapurniotu, A. Iapp Mimic Blocks A $\beta$ Cytotoxic Self-Assembly: Cross-Suppression of Amyloid Toxicity of A $\beta$ and Iapp Suggests a Molecular Link between Alzheimer's Disease and Type Ii Diabetes. Angew. Chem. Int. Ed. Engl. 2007, 46, 1246-1252. [CrossRef] [PubMed]

18. Richman, M.; Wilk, S.; Chemerovski, M.; Warmlander, S.K.; Wahlstrom, A.; Graslund, A.; Rahimipour, S. In Vitro and Mechanistic Studies of an Antiamyloidogenic Self-Assembled Cyclic D, L-A-Peptide Architecture. J. Am. Chem. Soc. 2013, 135, 3474-3484. [CrossRef]

19. Liu, W.; Dong, X.; Sun, Y. D-Enantiomeric Rthlvffark-Nh 2 : A Potent Multifunctional Decapeptide Inhibiting Cu ${ }^{2+}-\mathrm{Mediated}$ Amyloid B-Protein Aggregation and Rmodeling Cuㄹ-.Mediated Amyloid B Aggregates. ACS Chem. Neurosci. 2019, 10, $1390-1401$. [CrossRef]

20. Buxbaum, J.N.; Ye, Z.; Reixach, N.; Friske, L.; Levy, C.; Das, P.; Golde, T.; Masliah, E.; Roberts, A.R.; Bartfai, T. Transthyretin Protects Alzheimer's Mice from the Behavioral and Biochemical Effects of A $\beta$ Toxicity. Proc. Natl. Acad. Sci. USA 2008, 105, 2681-2686. [CrossRef]

21. Luo, J.; Warmlander, S.K.; Graslund, A.; Abrahams, J.P. Human Lysozyme Inhibits the In Vitro Aggregation of A $\beta$ Peptides, Which in Vivo Are Associated with Alzheimer's Disease. Chem. Commun. 2013, 49, 6507-6509. [CrossRef] [PubMed]

22. Wang, W.; Dong, X.; Sun, Y. Modification of Serum Albumin by High Conversion of Carboxyl to Amino Groups Creates a Potent Inhibitor of Amyloid B-Protein Fbrillogenesis. Bioconjug. Chem. 2019, 30, 1477-1488. [CrossRef] [PubMed] 
23. Gronwall, C.; Jonsson, A.; Lindstrom, S.; Gunneriusson, E.; Stahl, S.; Herne, N. Selection and Characterization of Affibody Ligands Binding to Alzheimer Amyloid B Peptides. J. Biotechnol. 2007, 128, 162-183. [CrossRef]

24. Fan, Y.; Wu, D.; Yi, X.; Tang, H.; Wu, L.; Xia, Y.; Wang, Z.; Liu, Q.; Zhou, Z.; Wang, J. Tmpyp Inhibits Amyloid-B Aggregation and Alleviates Amyloid-Induced Cytotoxicity. ACS Omega 2017, 2, 4188-4195. [CrossRef] [PubMed]

25. Taniguchi, A.; Shimizu, Y.; Oisaki, K.; Sohma, Y.; Kanai, M. Switchable Photooxygenation Catalysts That Sense Higher-Order Amyloid Structures. Nat. Chem. 2016, 8, 974-982. [CrossRef] [PubMed]

26. Taniguchi, A.; Sasaki, D.; Shiohara, A.; Iwatsubo, T.; Tomita, T.; Sohma, Y.; Kanai, M. Attenuation of the Aggregation and Neurotoxicity of Amyloid-B Peptides by Catalytic Photooxygenation. Angew. Chem. Int. Ed. Engl. 2014, 53, 1382-1385. [CrossRef] [PubMed]

27. Lee, J.S.; Lee, B.I.; Park, C.B. Photo-Induced Inhibition of Alzheimer's B-Amyloid Aggregation In Vitro by Rose Bengal. Biomaterials 2015, 38, 43-49. [CrossRef]

28. Lee, B.I.; Lee, S.; Suh, Y.S.; Lee, J.S.; Kim, A.-k.; Kwon, O.Y.; Yu, K.; Park, C.B. Photoexcited Porphyrins as a Strong Suppressor of B-Amyloid Aggregation and Synaptic Toxicity. Angew. Chem. 2015, 127, 11634-11638. [CrossRef]

29. Lee, B.I.; Suh, Y.S.; Chung, Y.J.; Yu, K.; Park, C.B. Shedding Light on Alzheimer's B-Amyloidosis: Photosensitized Methylene Blue Inhibits Self-Assembly of B-Amyloid Peptides and Disintegrates Their Aggregates. Sci. Rep. 2017, 7, 7523. [CrossRef]

30. Zorkina, Y.; Abramova, O.; Ushakova, V.; Morozova, A.; Zubkov, E.; Valikhov, M.; Melnikov, P.; Majouga, A.; Chekhonin, V. Nano Carrier Drug Delivery Systems for the Treatment of Neuropsychiatric Disorders: Advantages and Limitations. Molecules 2020, 25, 5294. [CrossRef] [PubMed]

31. Sun, J.; Wei, C.; Liu, Y.; Xie, W.; Xu, M.; Zhou, H.; Liu, J. Progressive Release of Mesoporous Nano-Selenium Delivery System for the Multi-Channel Synergistic Treatment of Alzheimer's Disease. Biomaterials 2019, 197, 417-431. [CrossRef] [PubMed]

32. Zagorska, A.; Jaromin, A. Perspectives for New and More Efficient Multifunctional Ligands for Alzheimer's Disease Therapy. Molecules 2020, 25, 3337. [CrossRef]

33. Manek, E.; Darvas, F.; Petroianu, G.A. Use of Biodegradable, Chitosan-Based Nanoparticles in the Treatment of Alzheimer's Disease. Molecules 2020, 25, 4866. [CrossRef] [PubMed]

34. Wu, W.H.; Sun, X.; Yu, Y.P.; Hu, J.; Zhao, L.; Liu, Q.; Zhao, Y.F.; Li, Y.M. Tio2 Nanoparticles Promote Beta-Amyloid Fibrillation In Vitro. Biochem. Biophys. Res. Commun. 2008, 373, 315-318. [CrossRef]

35. Daniel, M.-C.; Astruc, D. Gold Nanoparticles: Assembly, Supramolecular Chemistry, Quantum-Size-Related Properties, and Applications toward Biology, Catalysis, and Nanotechnology. Chem. Rev. 2004, 104, 293-346. [CrossRef] [PubMed]

36. Dykmana, L.; Khlebtsov, N. Gold Nanoparticles in Biomedical Applications: Recent Advances and Perspectives. Chem. Soc. Rev. 2012, 41, 2256-2282. [CrossRef]

37. Lee, H.; Kim, Y.; Park, A.; Nam, J.M.; Kim, Y.; Park, A.; Nam, J.M. Amyloid-B Aggregation with Gold Nanoparticles on Brain Lipid Bilayer. Small 2014, 10, 1779-1789. [CrossRef]

38. Mirsadeghi, S.; Dinarvand, R.; Ghahremani, M.H.; Hormozi-Nezhad, M.R.; Mahmoudi, Z.; Hajipour, M.J.; Atyabi, F.; Ghavami, M.; Mahmoudi, M. Protein Corona Composition of Gold Nanoparticles/Nanorods Affects Amyloid Beta Fibrillation Process. Nanoscale 2015, 7, 5004-5013. [CrossRef]

39. Kim, Y.; Park, J.H.; Lee, H.; Nam, J.M. How Do the Size, Charge and Shape of Nanoparticles Affect Amyloid Beta Aggregation on Brain Lipid Bilayer? Sci. Rep. 2016, 6, 19548. [CrossRef]

40. Gao, G.; Zhang, M.; Gong, D.; Chen, R.; Hu, X.; Sun, T. The Size-Effect of Gold Nanoparticles and Nanoclusters in the Inhibition of Amyloid-Beta Fibrillation. Nanoscale 2017, 9, 4107-4113. [CrossRef]

41. Liao, Y.H.; Chang, Y.J.; Yoshiike, Y.; Chang, Y.C.; Chen, Y.R. Negatively Charged Gold Nanoparticles Inhibit Alzheimer's Amyloid-B Fibrillization, Induce Fibril Dissociation, and Mitigate Neurotoxicity. Small 2012, 8, 3631-3639. [CrossRef]

42. Ma, Q.; Wei, G.; Yang, X. Influence of Au Nanoparticles on the Aggregation of Amyloid-Beta-(25-35) Peptides. Nanoscale 2013, 5, 10397-10403. [CrossRef]

43. Wang, W.; Han, Y.; Fan, Y.; Wang, Y. Effects of Gold Nanospheres and Nanocubes on Amyloid-Beta Peptide Fibrillation. Langmuir 2019, 35, 2334-2342. [CrossRef]

44. Liu, Y.; He, G.; Zhang, Z.; Yin, H.; Liu, H.; Chen, J.; Zhang, S.; Yang, B.; Xu, L.-P.; Zhang, X. Size-Effect of Gold Nanorods on Modulating the Kinetic Process of Amyloid-B Aggregation. Chem. Phys. Lett. 2019, 734, 136702. [CrossRef]

45. Bellucci, L.; Ardevol, A.; Parrinello, M.; Lutz, H.; Lu, H.; Weidner, T.; Corni, S. The Interaction with Gold Suppresses Fiber-Like Conformations of the Amyloid B(16-22) Peptide. Nanoscale 2016, 8, 8737-8748. [CrossRef]

46. Song, M.; Sun, Y.; Luo, Y.; Zhu, Y.; Liu, Y.; Li, H. Exploring the Mechanism of Inhibition of Au Nanoparticles on the Aggregation of Amyloid-B(16-22) Peptides at the Atom Level by All-Atom Molecular Dynamics. Int. J. Mol. Sci. 2018, 19, 1815. [CrossRef] [PubMed]

47. Anand, B.G.; Wu, Q.; Karthivashan, G.; Shejale, K.P.; Amidian, S.; Wille, H.; Kar, S. Mimosine Functionalized Gold Nanoparticles (Mimo-Aunps) Suppress B-Amyloid Aggregation and Neuronal Toxicity. Bioact. Mater. 2021, 6, 4491-4505. [CrossRef] [PubMed]

48. Palmal, S.; Maity, A.R.; Singh, B.K.; Basu, S.; Jana, N.R.; Jana, N.R. Inhibition of Amyloid Fibril Growth and Dissolution of Amyloid Fibrils by Curcumin-Gold Nanoparticles. Chem. Eur. J. 2014, 20, 6184-6191. [CrossRef] [PubMed]

49. Xiong, N.; Zhao, Y.; Dong, X.; Zheng, J.; Sun, Y. Design of a Molecular Hybrid of Dual Peptide Inhibitors Coupled on Aunps for Enhanced Inhibition of Amyloid B-Protein Aggregation and Cytotoxicity. Small 2017, 13, 1601666. [CrossRef] 
50. Adura, C.; Guerrero, S.; Salas, E.; Medel, L.; Riveros, A.; Mena, J.; Arbiol, J.; Albericio, F.; Giralt, E.; Kogan, M.J. Stable Conjugates of Peptides with Gold Nanorods for Biomedical Applications with Reduced Effects on Cell Viability. ACS Appl. Mater. Inter. 2013, 5, 4076-4085. [CrossRef]

51. Guerrero, S.; Araya, E.; Fiedler, J.L.; Arias, J.I.; Adura, C.; Albericio, F.; Giralt, E.; Arias, J.L.; Fernandez, M.S.; Kogan, M.J. Improving the Brain Delivery of Gold Nanoparticles by Conjugation with an Amphipathic Peptide. Nanomedicine 2010, 5, 897-913. [CrossRef] [PubMed]

52. Olmedo, I.; Araya, E.; Sanz, F.; Medina, E.; Arbiol, J.; Toledo, P.; Alvarez-Lueje, A.; Giralt, E.; Kogan, M.J. How Changes in the Sequence of the Peptide Clpffd-Nh 2 Can Modify the Conjugation and Stability of Gold Nanoparticles and Their Affinity for Beta-Amyloid Fibrils. Bioconjug. Chem. 2008, 19, 1154-1163. [CrossRef] [PubMed]

53. Kogan, M.J.; Bastus, N.G.; Amigo, R.; Grillo-Bosch, D.; Araya, E.; Turiel, A.; Labarta, A.; Giralt, E.; Puntes, V.F. NanoparticleMediated Local and Remote Manipulation of Protein Aggregation. Nano Lett. 2006, 6, 110-115. [CrossRef]

54. Araya, E.; Olmedo, I.; Bastus, N.G.; Guerrero, S.; Puntes, V.F.; Giralt, E.; Kogan, M.J. Gold Nanoparticles and Microwave Irradiation Inhibit Beta-Amyloid Amyloidogenesis. Nanoscale Res. Lett. 2008, 3, 435-443. [CrossRef]

55. Triulzi, R.C.; Dai, Q.; Zou, J.; Leblanc, R.M.; Gu, Q.; Orbulescu, J.; Huo, Q. Photothermal Ablation of Amyloid Aggregates by Gold Nanoparticles. Colloids Surf. B 2008, 63, 200-208. [CrossRef]

56. Ruff, J.; Hassan, N.; Morales-Zavala, F.; Steitz, J.; Araya, E.; Kogan, M.J.; Simon, U. Clpffd-Peg Functionalized Nir-Absorbing Hollow Gold Nanospheres and Gold Nanorods Inhibit B-Amyloid Aggregation. J. Mater. Chem. B 2018, 6, 2432-2443. [CrossRef]

57. Yin, T.; Xie, W.; Sun, J.; Yang, L.; Liu, J. Penetratin Peptide-Functionalized Gold Nanostars: Enhanced Bbb Permeability and Nir Photothermal Treatment of Alzheimer's Disease Using Ultralow Irradiance. ACS Appl. Mater. Inter. 2016, 8, 19291-19302. [CrossRef]

58. Lin, D.; He, R.; Li, S.; Xu, Y.; Wang, J.; Wei, G.; Ji, M.; Yang, X. Highly Efficient Destruction of Amyloid-B Fibrils by Femtosecond Laser-Induced Nanoexplosion of Gold Nanorods. ACS Chem. Neurosci. 2016, 7, 1728-1736. [CrossRef]

59. Bush, A.I.; Pettingell, W.H.; Multhaup, G.; d ParadisParadis, M.; Vonsattel, J.P.; Gusella, J.F.; Beyreuther, K.; Masters, C.L.; Tanzi, R.E. Rapid Induction of Alzheimer A $\beta$ Amyloid Formation by Zinc. Science 1994, 265, 1464-1467. [CrossRef]

60. Geng, J.; Li, M.; Wu, L.; Ren, J.; Qu, X. Liberation of Copper from Amyloid Plaques: Making a Risk Factor Useful for Alzheimer's Disease Treatment. J. Med. Chem. 2012, 55, 9146-9155. [CrossRef]

61. Kepp, K.P. Bioinorganic Chemistry of Alzheimer's Disease. Chem. Rev. 2012, 112, 5193-5239. [CrossRef]

62. Cahoon, L. The Curious Case of Clioquinol. Nat. Med. 2009, 15, 356. [CrossRef] [PubMed]

63. Dedeoglu, A.; Cormier, K.; Payton, S.; Tseitlin, K.A.; Kremsky, J.N.; Lai, L.; Li, X.; Moir, R.D.; Tanzi, R.E.; Bush, A.I.; et al. Preliminary Studies of a Novel Bifunctional Metal Chelator Targeting Alzheimer's Amyloidogenesis. Exp. Gerontol. 2004, 39, 1641-1649. [CrossRef] [PubMed]

64. Shi, P.; Li, M.; Ren, J.; Qu, X. Gold Nanocage-Based Dual Responsive “Caged Metal Chelator"Release System: Noninvasive Remote Control with near Infrared for Potential Treatment of Alzheimer's Disease. Adv. Funct. Mater. 2013, 23, 5412-5419. [CrossRef]

65. Hao, S.; Li, X.; Han, A.; Yang, Y.; Fang, G.; Liu, J.; Wang, S. CLVFFA-Functionalized Gold Nanoclusters Inhibit A $\beta_{40}$ Fibrillation, Fibrils' Prolongation, and Mature Fibrils' Disaggregation. ACS Chem. Neurosci. 2019, 10, 4633-4642. [CrossRef] [PubMed]

66. Sun, T.; He, M.; Luo, Z.; Ma, Z.; Gao, G.; Zhang, W. Au ${ }_{23}(\mathrm{Cr})_{14}$ Nanocluster Restores Fibril A $\beta$ 's Unfolded State with Abolished Cytotoxicity and Dissolves Endogenous A $\beta$ Plaques. Natl. Sci. Rev. 2020, 7, 763-774. [CrossRef]

67. Li, Q.; Liu, L.; Zhang, S.; Xu, M.; Wang, X.; Wang, C.; Besenbacher, F.; Dong, M. Modulating A $\beta_{33-42}$ Peptide Assembly by Graphene Oxide. Chem. Eur. J. 2014, 20, 7236-7240. [CrossRef] [PubMed]

68. Bag, S.; Sett, A.; DasGupta, S.; Dasgupta, S. Hydropathy: The Controlling Factor Behind the Inhibition of A $\beta$ Fibrillation by Graphene Oxide. RSC Adv. 2016, 6, 103242-103252. [CrossRef]

69. Yu, X.; Wang, Q.; Lin, Y.; Zhao, J.; Zhao, C.; Zheng, J. Structure, Orientation, and Surface Interaction of Alzheimer Amyloid-Beta Peptides on the Graphite. Langmuir 2012, 28, 6595-6605. [CrossRef]

70. Yang, Z.; Ge, C.; Liu, J.; Chong, Y.; Gu, Z.; Jimenez-Cruz, C.A.; Chai, Z.; Zhou, R. Destruction of Amyloid Fibrils by Graphene through Penetration and Extraction of Peptides. Nanoscale 2015, 7, 18725-18737. [CrossRef]

71. Mahmoudi, M.; Akhavan, O.; Ghavami, M.; Rezaee, F.; Ghiasi, S.M. Graphene Oxide Strongly Inhibits Amyloid Beta Fibrillation. Nanoscale 2012, 4, 7322-7325. [CrossRef] [PubMed]

72. Wang, J.; Cao, Y.; Li, Q.; Liu, L.; Dong, M. Size Effect of Graphene Oxide on Modulating Amyloid Peptide Assembly. Chem. Eur. J. 2015, 21, 9632-9637. [CrossRef]

73. Qing, G.; Zhao, S.; Xiong, Y.; Lv, Z.; Jiang, F.; Liu, Y.; Chen, H.; Zhang, M.; Sun, T. Chiral Effect at Protein/Graphene Interface: A Bioinspired Perspective to Understand Amyloid Formation. J. Am. Chem. Soc. 2014, 136, 10736-10742. [CrossRef] [PubMed]

74. Li, M.; Yang, X.; Ren, J.; Qu, K.; Qu, X. Using Graphene Oxide High near-Infrared Absorbance for Photothermal Treatment of Alzheimer's Disease. Adv. Mater. 2012, 24, 1722-1728. [CrossRef]

75. Xu, C.; Shi, P.; Li, M.; Ren, J.; Qu, X. A Cytotoxic Amyloid Oligomer Self-Triggered and Nir-Enhanced Amyloidosis Therapeutic System. Nano Res. 2015, 8, 2431-2444. [CrossRef]

76. Li, J.; Han, Q.; Wang, X.; Yu, N.; Yang, L.; Yang, R.; Wang, C. Reduced Aggregation and Cytotoxicity of Amyloid Peptides by Graphene Oxide/Gold Nanocomposites Prepared by Pulsed Laser Ablation in Water. Small 2014, 10, 4386-4394. [CrossRef] 
77. Ahmad, I.; Mozhi, A.; Yang, L.; Han, Q.; Liang, X.; Li, C.; Yang, R.; Wang, C. Graphene Oxide-Iron Oxide Nanocomposite as an Inhibitor of A $\beta 42$ Amyloid Peptide Aggregation. Colloids Surf. B 2017, 159, 540-545. [CrossRef] [PubMed]

78. Liu, F.; Wang, W.; Sang, J.; Jia, L.; Lu, F. Hydroxylated Single-Walled Carbon Nanotubes Inhibit A $\beta_{42}$ Fibrillogenesis, Disaggregate Mature Fibrils, and Protect against A $\beta_{42}$-Induced Cytotoxicity. ACS Chem. Neurosci. 2019, 10, 588-598. [CrossRef]

79. Kam, N.W.; O'Connell, M.; Wisdom, J.A.; Dai, H. Carbon Nanotubes as Multifunctional Biological Transporters and near-Infrared Agents for Selective Cancer Cell Destruction. Proc. Natl. Acad. Sci. USA 2005, 102, 11600-11605. [CrossRef]

80. Luo, J.; Warmlander, S.K.; Yu, C.H.; Muhammad, K.; Graslund, A.; Pieter Abrahams, J. The Abeta Peptide Forms Non-Amyloid Fibrils in the Presence of Carbon Nanotubes. Nanoscale 2014, 6, 6720-6726. [CrossRef] [PubMed]

81. Xie, L.; Lin, D.; Luo, Y.; Li, H.; Yang, X.; Wei, G. Effects of Hydroxylated Carbon Nanotubes on the Aggregation of A $\beta_{16-22}$ Peptides: A Combined Simulation and Experimental Study. Biophys. J. 2014, 107, 1930-1938. [CrossRef] [PubMed]

82. Ma, M.; Gao, N.; Li, X.; Liu, Z.; Pi, Z.; Du, X.; Ren, J.; Qu, X. A Biocompatible Second near-Infrared Nanozyme for Spatiotemporal and Non-Invasive Attenuation of Amyloid Deposition through Scalp and Skull. ACS Nano 2020, 14, 9894-9903. [CrossRef] [PubMed]

83. Sun, Y.; Qian, Z.; Wei, G. The Inhibitory Mechanism of a Fullerene Derivative against Amyloid-Beta Peptide Aggregation: An Atomistic Simulation Study. Phys. Chem. Chem. Phys. 2016, 18, 12582-12591. [CrossRef] [PubMed]

84. Xie, L.; Luo, Y.; Lin, D.; Xi, W.; Yang, X.; Wei, G. The Molecular Mechanism of Fullerene-Inhibited Aggregation of Alzheimer's B-Amyloid Peptide Fragment. Nanoscale 2014, 6, 9752-9762. [CrossRef] [PubMed]

85. Kim, J.E.; Lee, M. Fullerene Inhibits B-Amyloid Peptide Aggregation. Biochem. Biophys. Res. Commun. 2003, 303, 576-579. [CrossRef]

86. Podolski, I.Y.; Podlubnaya, Z.A.; Kosenko, E.A.; Mugantseva, E.A.; Makarova, E.G.; Marsagishvili, L.G.; Shpagina, M.D.; Kaminsky, Y.G.; Andrievsky, G.V.; Klochkov, V.K. Effects of Hydrated Forms of $\mathrm{C}_{60}$ Fullerene on Amyloid B-Peptide Fibrillization In Vitro and Performance of the Cognitive Task. J. Nanosci. Nanotechnol. 2007, 7, 1479-1485. [CrossRef]

87. Bobylev, A.G.; Kornev, A.B.; Bobyleva, L.G.; Shpagina, M.D.; Fadeeva, I.S.; Fadeev, R.S.; Deryabin, D.G.; Balzarini, J.; Troshin, P.A.; Podlubnaya, Z.A. Fullerenolates: Metallated Polyhydroxylated Fullerenes with Potent Anti-Amyloid Activity. Org. Biomol. Chem. 2011, 9, 5714-5719. [CrossRef]

88. Bednarikova, Z.; Huy, P.D.; Mocanu, M.M.; Fedunova, D.; Li, M.S.; Gazova, Z. Fullerenol C ${ }_{60}(\mathrm{Oh})_{16}$ Prevents Amyloid Fibrillization of $\mathrm{A} \beta_{40}$-In Vitro and in Silico Approach. Phys. Chem. Chem. Phys. 2016, 18, 18855-18867. [CrossRef]

89. Melchor, M.-H.; Susana, F.-G.; Francisco, G.-S.; Hiram I, B.; Norma, R.-F.; Jorge A, L.-R.; Perla Y, L.-C.; Gustavo, B.-I. Fullerenemalonates Inhibit Amyloid Beta Aggregation, In Vitro and in Silico Evaluation. RSC Adv. 2018, 8, 39667-39677. [CrossRef]

90. Bobylev, A.G.; Kraevaya, O.A.; Bobyleva, L.G.; Khakina, E.A.; Fadeev, R.S.; Zhilenkov, A.V.; Mishchenko, D.V.; Penkov, N.V.; Teplov, I.Y.; Yakupova, E.I.; et al. Anti-amyloid Activities of Three Different Types of Water-Soluble Fullerene Derivatives. Colloids Surf. B 2019, 183, 110426. [CrossRef]

91. Prat, F.; Hou, C.-C.; Foote, C.S. Determination of the Quenching Rate Constants of Singlet Oxygen by Derivatized Nucleosides in Nonaqueous Solution. J. Am. Chem. Soc. 1997, 119, 5051-5052. [CrossRef]

92. Tanimoto, S.; Sakai, S.; Matsumura, S.; Takahashi, D.; Toshima, K. Target-Selective Photo-Degradation of Hiv-1 Protease by a Fullerene-Sugar Hybrid. Chem. Commun. 2008, 5767-5769. [CrossRef] [PubMed]

93. Ishida, Y.; Tanimoto, S.; Takahashi, D.; Toshima, K. Photo-Degradation of Amyloid B by a Designed Fullerene-Sugar Hybrid. MedChem Comm 2010, 1, 212. [CrossRef]

94. Ishida, Y.; Fujii, T.; Oka, K.; Takahashi, D.; Toshima, K. Inhibition of Amyloi B Aggregation and Cytotoxicity by Photodegradation Using a Designed Fullerene Derivative. Chem. Asian J. 2011, 6, 2312-2315. [CrossRef]

95. Du, Z.; Gao, N.; Wang, X.; Ren, J.; Qu, X. Near-Infrared Switchable Fullerene-Based Synergy Therapy for Alzheimer's Disease. Small 2018, 14, 1801852. [CrossRef]

96. Xu, X.; Ray, R.; Gu, Y.; Ploehn, H.J.; Gearheart, L.; Raker, K.; Scrivens, W.A. Electrophoretic Analysis and Purification of Fluorescent Single-Walled Carbon Nanotube Fragments. J. Am. Chem. Soc. 2004, 126, 12736-12737. [CrossRef]

97. Liu, Y.; Xu, L.P.; Dai, W.; Dong, H.; Wen, Y.; Zhang, X. Graphene Quantum Dots for the Inhibition of B Amyloid Aggregation. Nanoscale 2015, 7, 19060-19065. [CrossRef]

98. Sun, D.; Zhang, W.; Yu, Q.; Chen, X.; Xu, M.; Zhou, Y.; Liu, J. Chiral Penicillamine-Modified Selenium Nanoparticles Enantioselectively Inhibit Metal-Induced Amyloid Beta Aggregation for Treating Alzheimer's Disease. J. Colloid Interface Sci. 2017, 505, 1001-1010. [CrossRef]

99. Malishev, R.; Arad, E.; Bhunia, S.K.; Shaham-Niv, S.; Kolusheva, S.; Gazit, E.; Jelinek, R. Chiral Modulation of Amyloid Beta Fibrillation and Cytotoxicity by Enantiomeric Carbon Dots. Chem. Commun. 2018, 54, 7762-7765. [CrossRef] [PubMed]

100. Xiao, S.; Zhou, D.; Luan, P.; Gu, B.; Feng, L.; Fan, S.; Liao, W.; Fang, W.; Yang, L.; Tao, E.; et al. Graphene Quantum Dots Conjugated Neuroprotective Peptide Improve Learning and Memory Capability. Biomaterials 2016, 106, 98-110. [CrossRef] [PubMed]

101. Gao, W.; Wang, W.; Dong, X.; Sun, Y. Nitrogen-Doped Carbonized Polymer Dots: A Potent Scavenger and Detector Targeting Alzheimer's B-Amyloid Plaques. Small 2020, 16, e2002804. [CrossRef] [PubMed]

102. Chung, Y.J.; Kim, K.; Lee, B.I.; Park, C.B. Carbon Nanodot-Sensitized Modulation of Alzheimer's B-Amyloid Self-Assembly, Disassembly, and Toxicity. Small 2017, 13, 1700983. [CrossRef] [PubMed] 
103. Chung, Y.J.; Lee, C.H.; Lim, J.; Jang, J.; Kang, H.; Park, C.B. Photomodulating Carbon Dots for Spatiotemporal Suppression of Alzheimer's B-Amyloid Aggregation. ACS Nano 2020, 14, 16973-16983. [CrossRef]

104. Mahmoudi, M.; Quinlan-Pluck, F.; Monopoli, M.P.; Sheibani, S.; Vali, H.; Dawson, K.A.; Lynch, I. Influence of the Physiochemical Properties of Superparamagnetic Iron Oxide Nanoparticles on Amyloid Beta Protein Fibrillation in Solution. ACS Chem. Neurosci. 2013, 4, 475-485. [CrossRef] [PubMed]

105. Margel, S.; Skaat, H.; Corem-Salkmon, E.; Grinberg, I.; Last, D.; Goez, D.; Mardor, Y. Antibody-Conjugated, Dual-Modal, near-Infrared Fluorescent Iron Oxide Nanoparticles for Antiamyloidgenic Activity and Specific Detection of Amyloid-B Fibrils. Int. J. Nanomed. 2013, 8, 4063-4076. [CrossRef] [PubMed]

106. Skaat, H.; Shafir, G.; Margel, S. Acceleration and Inhibition of Amyloid-B Fibril Formation by Peptide-Conjugated FluorescentMaghemite Nanoparticles. J. Nanopart. Res. 2011, 13, 3521-3534. [CrossRef]

107. Halevas, E.; Mavroidi, B.; Nday, C.M.; Tang, J.; Smith, G.C.; Boukos, N.; Litsardakis, G.; Pelecanou, M.; Salifoglou, A. Modified Magnetic Core-Shell Mesoporous Silica Nano-Formulations with Encapsulated Quercetin Exhibit Anti-Amyloid and Antioxidant Activity. J. Inorg. Biochem. 2020, 213, 111271. [CrossRef]

108. Hirohata, M.; Hasegawa, K.; Tsutsumi-Yasuhara, S.; Ohhashi, Y.; Ookoshi, T.; Ono, K.; Yamada, M.; Naiki, H. The AntiAmyloidogenic Effect Is Exerted against Alzheimer's Beta-Amyloid Fibrils In Vitro by Preferential and Reversible Binding of Flavonoids to the Amyloid Fibril Structure. Biochemistry 2007, 46, 1888-1899. [CrossRef]

109. Li, M.; Liu, Z.; Ren, J.; Qu, X. Inhibition of Metal-Induced Amyloid Aggregation Using Light-Responsive Magnetic Nanoparticle Prochelator Conjugates. Chem. Sci. 2012, 3, 868-873. [CrossRef]

110. Loynachan, C.N.; Romero, G.; Christiansen, M.G.; Chen, R.; Ellison, R.; O’Malley, T.T.; Froriep, U.P.; Walsh, D.M.; Anikeeva, P. Targeted Magnetic Nanoparticles for Remote Magnetothermal Disruption of Amyloid-B Aggregates. Adv. Healthc. Mater. 2015, 4, 2100-2109. [CrossRef]

111. Chen, R.; Romero, G.; Christiansen, M.G.; Mohr, A.; Anikeeva, P. Wireless Magnetothermal Deep Brain Stimulation. Science 2015, 347, 1477-1480. [CrossRef]

112. Riedinger, A.; Guardia, P.; Curcio, A.; Garcia, M.A.; Cingolani, R.; Manna, L.; Pellegrino, T. Subnanometer Local Temperature Probing and Remotely Controlled Drug Release Based on Azo-Functionalized Iron Oxide Nanoparticles. Nano Lett. 2013, 13, 2399-2406. [CrossRef]

113. Dyne, E.; Prakash, P.S.; Li, J.; Yu, B.; Schmidt, T.L.; Huang, S.; Kim, M.H. Mild Magnetic Nanoparticle Hyperthermia Promotes the Disaggregation and Microglia-Mediated Clearance of Beta-Amyloid Plaques. Nanomedicine 2021, 34, 102397. [CrossRef]

114. Du, Z.; Gao, N.; Guan, Y.; Ding, C.; Sun, Y.; Ren, J.; Qu, X. Rational Design of a "Sense and Treat" System to Target Amyloid Aggregates Related to Alzheimer's Disease. Nano Res. 2018, 11, 1987-1997. [CrossRef]

115. Rhule, J.T.; Hill, C.L.; Judd, D.A.; Schinazi, R.F. Polyoxometalates in Medicine. Chem. Rev. 1998, 98, 327-358. [CrossRef] [PubMed]

116. Judd, D.A.; Nettles, J.H.; Nevins, N.; Snyder, J.P.; Liotta, D.C.; Tang, J.; Ermolieff, J.; Schinazi, R.F.; Hill, C.L. Polyoxometalate Hiv-1 Protease Inhibitors. A New Mode of Protease Inhibition. J. Am. Chem. Soc. 2001, 123, 886-897. [CrossRef]

117. Geng, J.; Li, M.; Ren, J.; Wang, E.; Qu, X. Polyoxometalates as Inhibitors of the Aggregation of Amyloid Beta Peptides Associated with Alzheimer's Disease. Angew. Chem. Int. Ed. Engl. 2011, 50, 4184-4188. [CrossRef]

118. Zhou, Y.; Zheng, L.; Han, F.; Zhang, G.; Ma, Y.; Yao, J.; Keita, B.; de Oliveira, P.; Nadjo, L. Inhibition of Amyloid-B Protein Fibrillization Upon Interaction with Polyoxometalates Nanoclusters. Colloids Surface A 2011, 375, 97-101. [CrossRef]

119. Gao, N.; Sun, H.; Dong, K.; Ren, J.; Duan, T.; Xu, C.; Qu, X. Transition-Metal-Substituted Polyoxometalate Derivatives as Functional Anti-Amyloid Agents for Alzheimer's Disease. Nat. Commun. 2014, 5, 3422. [CrossRef]

120. Zhao, J.; Li, K.; Wan, K.; Sun, T.; Zheng, N.; Zhu, F.; Ma, J.; Jiao, J.; Li, T.; Ni, J.; et al. Organoplatinum-substituted polyoxometalate inhibits B-amyloid aggregation for Alzheimer's therapy. Angew. Chem. 2019, 131, 18200-18207. [CrossRef]

121. Chen, Q.; Yang, L.; Zheng, C.; Zheng, W.; Zhang, J.; Zhou, Y.; Liu, J. Mo Polyoxometalate Nanoclusters Capable of Inhibiting the Aggregation of A $\beta$-Peptide Associated with Alzheimer's Disease. Nanoscale 2014, 6, 6886-6897. [CrossRef]

122. Bernardini, G.; Wedd, A.G.; Zhao, C.; Bond, A.M. Photochemical Oxidation of Water and Reduction of Polyoxometalate Anions at Interfaces of Water with Ionic Liquids or Diethylether. Proc. Natl. Acad. Sci. USA 2012, 109, 11552-11557. [CrossRef]

123. Bonchio, M.; Carraro, M.; Conte, V.; Scorrano, G. Aerobic Photooxidation in Water by Polyoxotungstates: The Case of Uracil. Eur. J. Org. Chem. 2005, 2005, 4897-4903. [CrossRef]

124. Li, M.; Xu, C.; Ren, J.; Wang, E.; Qu, X. Photodegradation of Beta-Sheet Amyloid Fibrils Associated with Alzheimer's Disease by Using Polyoxometalates as Photocatalysts. Chem. Commun. 2013, 49, 11394-11396. [CrossRef]

125. Ma, M.; Gao, N.; Sun, Y.; Du, X.; Ren, J.; Qu, X. Redox-Activated near-Infrared-Responsive Polyoxometalates Used for Photothermal Treatment of Alzheimer's Disease. Adv. Healthc. Mater. 2018, 7, e1800320. [CrossRef] [PubMed]

126. Li, M.; Xu, C.; Wu, L.; Ren, J.; Wang, E.; Qu, X. Self-Assembled Peptide-Polyoxometalate Hybrid Nanospheres: Two in One Enhances Targeted Inhibition of Amyloid Beta-Peptide Aggregation Associated with Alzheimer's Disease. Small 2013, 9, 3455-3461. [CrossRef]

127. Gao, N.; Sun, H.; Dong, K.; Ren, J.; Qu, X. Gold-Nanoparticle-Based Multifunctional Amyloid-B Inhibitor against Alzheimer's Disease. Chem. Eur. J. 2015, 21, 829-835. [CrossRef]

128. Li, M.; Guan, Y.; Zhao, A.; Ren, J.; Qu, X. Using Multifunctional Peptide Conjugated Au Nanorods for Monitoring Beta-Amyloid Aggregation and Chemo-Photothermal Treatment of Alzheimer's Disease. Theranostics 2017, 7, 2996-3006. [CrossRef] 
129. Xu, C.; Qu, X. Cerium Oxide Nanoparticle: A Remarkably Versatile Rare Earth Nanomaterial for Biological Applications. NPG Asia Mater. 2014, 6, e90. [CrossRef]

130. D'Angelo, B.; Santucci, S.; Benedetti, E.; Di Loreto, S.; Phani, R.; Falone, S.; Amicarelli, F.; Ceru, M.; Cimini, A. Cerium Oxide Nanoparticles Trigger Neuronal Survival in Ahuman Alzheimer Disease Model by Modulating Bdnf Pathway. Curr. Nanosci. 2009, 5, 167-176. [CrossRef]

131. Dowding, J.M.; Song, W.; Bossy, K.; Karakoti, A.; Kumar, A.; Kim, A.; Bossy, B.; Seal, S.; Ellisman, M.H.; Perkins, G.; et al. Cerium Oxide Nanoparticles Protect against A $\beta$-Induced Mitochondrial Fragmentation and Neuronal Cell Death. Cell Death Differ. 2014, 21, 1622-1632. [CrossRef]

132. Li, M.; Shi, P.; Xu, C.; Ren, J.; Qu, X. Cerium Oxide Caged Metal Chelator: Anti-Aggregation and Anti-Oxidation Integrated $\mathrm{H}_{2} \mathrm{O}_{2}$-Responsive Controlled Drug Release for Potential Alzheimer's Disease Treatment. Chem. Sci. 2013, 4, 2536-2542. [CrossRef]

133. Guan, Y.; Gao, N.; Ren, J.; Qu, X. Rationally Designed Cenp@Mnmos 4 Core-Shell Nanoparticles for Modulating Multiple Facets of Alzheimer's Disease. Chem. Eur. J. 2016, 22, 14523-14526. [CrossRef]

134. Absillis, G.; Parac-Vogt, T.N. Peptide Bond Hydrolysis Catalyzed by the Wells-Dawson $\mathrm{Zr}\left(\mathrm{A}_{2}-\mathrm{P}_{2} \mathrm{w}_{17} \mathrm{O}_{61}\right)_{2}$ Polyoxometalate. Inorg. Chem. 2012, 51, 9902-9910. [CrossRef]

135. Guan, Y.; Li, M.; Dong, K.; Gao, N.; Ren, J.; Zheng, Y.; Qu, X. Ceria/Poms Hybrid Nanoparticles as a Mimicking Metallopeptidase for Treatment of Neurotoxicity of Amyloid-B Peptide. Biomaterials 2016, 98, 92-102. [CrossRef] [PubMed]

136. Kim, D.; Kwon, H.J.; Hyeon, T. Magnetite/Ceria Nanoparticle Assemblies for Extracorporeal Cleansing of Amyloid-B in Alzheimer's Disease. Adv. Mater. 2019, 31, e1807965. [CrossRef] [PubMed]

137. Lim, Y.J.; Zhou, W.H.; Li, G.; Hu, Z.W.; Hong, L.; Yu, X.F.; Li, Y.M. Black Phosphorus Nanomaterials Regulate the Aggregation of Amyloid-B. ChemNanoMat 2019, 5, 606-611. [CrossRef]

138. Yang, J.; Liu, W.; Sun, Y.; Dong, X. Lvffark-Peg-Stabilized Black Phosphorus Nanosheets Potently Inhibit Amyloid-B Fibrillogenesis. Langmuir 2020, 36, 1804-1812. [CrossRef]

139. Wang, H.; Yang, X.; Shao, W.; Chen, S.; Xie, J.; Zhang, X.; Wang, J.; Xie, Y. Ultrathin Black Phosphorus Nanosheets for Efficient Singlet Oxygen Generation. J. Am. Chem. Soc. 2015, 137, 11376-11382. [CrossRef]

140. Sun, Z.; Xie, H.; Tang, S.; Yu, X.-F.; Guo, Z.; Shao, J.; Zhang, H.; Huang, H.; Wang, H.; Chu, P.K. Ultrasmall Black Phosphorus Quantum Dots: Synthesis and Use as Photothermal Agents. Angew. Chem. 2015, 127, 11688-11692. [CrossRef]

141. Sun, C.; Wen, L.; Zeng, J.; Wang, Y.; Sun, Q.; Deng, L.; Zhao, C.; Li, Z. One-Pot Solventless Preparation of Pegylated Black Phosphorus Nanoparticles for Photoacoustic Imaging and Photothermal Therapy of Cancer. Biomaterials 2016, 91, 81-89. [CrossRef]

142. Chen, W.; Ouyang, J.; Liu, H.; Chen, M.; Zeng, K.; Sheng, J.; Liu, Z.; Han, Y.; Wang, L.; Li, J.; et al. Black Phosphorus Nanosheet-Based Drug Delivery System for Synergistic Photodynamic/Photothermal/Chemotherapy of Cancer. Adv. Mater. 2017, 29, 1603864. [CrossRef]

143. Li, Y.; Du, Z.; Liu, X.; Ma, M.; Yu, D.; Lu, Y.; Ren, J.; Qu, X. Near-Infrared Activated Black Phosphorus as a Nontoxic Photo-Oxidant for Alzheimer's Amyloid-B Peptide. Small 2019, 15, 1901116. [CrossRef]

144. Mudedla, S.K.; Murugan, N.A.; Subramanian, V.; Agren, H. Destabilization of Amyloid Fibrils on Interaction with Mos2-Based Nanomaterials. RSC Adv. 2019, 9, 1613-1624. [CrossRef]

145. Wang, J.; Liu, L.; Ge, D.; Zhang, H.; Feng, Y.; Zhang, Y.; Chen, M.; Dong, M. Differential Modulating Effect of Mos 2 on Amyloid Peptide Assemblies. Chem. Eur. J. 2018, 24, 3397-3402. [CrossRef]

146. Liu, Y.; Zheng, Y.; Li, S.; Li, J.; Du, X.; Ma, Y.; Liao, G.; Wang, Q.; Yang, X.; Wang, K. Contradictory Effect of Gold NanoparticleDecorated Molybdenum Sulfide Nanocomposites on Amyloid-B-40 Aggregation. Chin. Chem. Lett. 2020, 31, 3113-3116. [CrossRef]

147. Chou, S.S.; Kaehr, B.; Kim, J.; Foley, B.M.; De, M.; Hopkins, P.E.; Huang, J.; Brinker, C.J.; Dravid, V.P. Chemically Exfoliated Mos 2 as near-Infrared Photothermal Agents. Angew. Chem. Int. Ed. Engl. 2013, 52, 4160-4164. [CrossRef]

148. Li, M.; Zhao, A.; Dong, K.; Li, W.; Ren, J.; Qu, X. Chemically Exfoliated Ws ${ }_{2}$ Nanosheets Efficiently Inhibit Amyloid B-Peptide Aggregation and Can Be Used for Photothermal Treatment of Alzheimer's Disease. Nano Res. 2015, 8, 3216-3227. [CrossRef]

149. Wang, X.; Han, Q.; Liu, X.; Wang, C.; Yang, R. Multifunctional Inhibitors of B-Amyloid Aggregation Based on Mos 2 /Aunr Nanocomposites with High near-Infrared Absorption. Nanoscale 2019, 11, 9185-9193. [CrossRef]

150. Suh, J.; Yoo, S.H.; Kim, M.G.; Jeong, K.; Ahn, J.Y.; Kim, M.-s.; Chae, P.S.; Lee, T.Y.; Lee, J.; Lee, J.; et al. Cleavage Agents for Soluble Oligomers of Amyloid B Peptides. Angew. Chem. 2007, 119, 7194-7197. [CrossRef]

151. Derrick, J.S.; Lee, J.; Lee, S.J.; Kim, Y.; Nam, E.; Tak, H.; Kang, J.; Lee, M.; Kim, S.H.; Park, K.; et al. Mechanistic Insights into Tunable Metal-Mediated Hydrolysis of Amyloid-B Peptides. J. Am. Chem. Soc. 2017, 139, 2234-2244. [CrossRef]

152. Ma, M.; Wang, Y.; Gao, N.; Liu, X.; Sun, Y.; Ren, J.; Qu, X. A near-Infrared-Controllable Artificial Metalloprotease Used for Degrading Amyloid-B Monomers and Aggregates. Chem. Eur. J. 2019, 25, 11852-11858. [CrossRef] [PubMed]

153. Han, Q.; Cai, S.; Yang, L.; Wang, X.; Qi, C.; Yang, R.; Wang, C. Molybdenum Disulfide Nanoparticles as Multifunctional Inhibitors against Alzheimer's Disease. ACS Appl. Mater. Inter. 2017, 9, 21116-21123. [CrossRef]

154. Chung, Y.J.; Lee, B.I.; Ko, J.W.; Park, C.B. Photoactive G-C $\mathrm{n}_{4}$ Nanosheets for Light-Induced Suppression of Alzheimer's B-Amyloid Aggregation and Toxicity. Adv. Healthc. Mater. 2016, 5, 1560-1565. [CrossRef]

155. Wang, J.; Zhang, Z.; Zhang, H.; Li, C.; Chen, M.; Liu, L.; Dong, M. Enhanced Photoresponsive Graphene Oxide-Modified G-C ${ }_{3} \mathrm{n}_{4}$ for Disassembly of Amyloid B Fibrils. ACS Appl. Mater. Inter. 2019, 11, 96-103. [CrossRef] 
156. Wang, J.; Feng, Y.; Tian, X.; Li, C.; Liu, L. Disassembling and Degradation of Amyloid Protein Aggregates Based on Gold Nanoparticle-Modified G-C $\mathrm{n}_{4}$. Colloids Surf. B 2020, 192, 111051. [CrossRef]

157. Li, M.; Guan, Y.; Ding, C.; Chen, Z.; Ren, J.; Qu, X. An Ultrathin Graphitic Carbon Nitride Nanosheet: A Novel Inhibitor of Metal-Induced Amyloid Aggregation Associated with Alzheimer's Disease. J. Mater. Chem. B 2016, 4, 4072-4075. [CrossRef]

158. Li, M.; Guan, Y.; Chen, Z.; Gao, N.; Ren, J.; Dong, K.; Qu, X. Platinum-Coordinated Graphitic Carbon Nitride Nanosheet Used for Targeted Inhibition of Amyloid B-Peptide Aggregation. Nano Res. 2016, 9, 2411-2423. [CrossRef]

159. Gong, L.; Zhang, X.; Ge, K.; Yin, Y.; Machuki, J.O.; Yang, Y.; Shi, H.; Geng, D.; Gao, F. Carbon Nitride-Based Nanocaptor: An Intelligent Nanosystem with Metal Ions Chelating Effect for Enhanced Magnetic Targeting Phototherapy of Alzheimer's Disease. Biomaterials 2021, 267, 120483. [CrossRef] [PubMed]

160. Wang, J.; Fan, Y.; Tan, Y.; Zhao, X.; Zhang, Y.; Cheng, C.; Yang, M. Porphyrinic Metal-Organic Framework Pcn-224 Nanoparticles for near-Infrared-Induced Attenuation of Aggregation and Neurotoxicity of Alzheimer's Amyloid-Beta Peptide. ACS Appl. Mater. Inter. 2018, 10, 36615-36621. [CrossRef] [PubMed]

161. Chen, Y.-Z.; Jiang, H.-L. Porphyrinic Metal-Organic Framework Catalyzed Heck-Reaction: Fluorescence “Turn-on” Sensing of $\mathrm{Cu}$ (Ii) Ion. Chem. Mater. 2016, 28, 6698-6704. [CrossRef]

162. Yu, D.; Guan, Y.; Bai, F.; Du, Z.; Gao, N.; Ren, J.; Qu, X. Metal-Organic Frameworks Harness Cu Chelating and Photooxidation against Amyloid B Aggregation in Vivo. Chem. Eur. J. 2019, 25, 3489-3495. [CrossRef] [PubMed]

163. Kowalczyk, J.; Grapsi, E.; Espargaro, A.; Caballero, A.B.; Juarez-Jimenez, J.; Busquets, M.A.; Gamez, P.; Sabate, R.; Estelrich, J. Dual Effect of Prussian Blue Nanoparticles on $\mathrm{A} \beta_{40}$ Aggregation: B-Sheet Fibril Reduction and Copper Dyshomeostasis Regulation. Biomacromolecules 2021, 22, 430-440. [CrossRef] [PubMed]

164. Prabhu, M.P.T.; Sarkar, N. Quantum Dots as Promising Theranostic Tools Againstamyloidosis:A Review. Protein Pept. Lett. 2019, 26, 555-563. [CrossRef] [PubMed]

165. Xiao, L.; Zhao, D.; Chan, W.H.; Choi, M.M.; Li, H.W. Inhibition of Beta 1-40 Amyloid Fibrillation with N-Acetyl-L-Cysteine Capped Quantum Dots. Biomaterials 2010, 31, 91-98. [CrossRef] [PubMed]

166. Ng, O.T.W.; Wong, Y.; Chan, H.M.; Cheng, J.; Qi, X.; Chan, W.H.; Yung, K.K.L.; Li, H.W. N-Acetyl-L-Cysteine Capped Quantum Dots Offer Neuronal Cell Protection by Inhibiting Beta(1-40) Amyloid Fibrillation. Biomater. Sci. 2013, 1, 577-580. [CrossRef]

167. Thakur, G.; Micic, M.; Yang, Y.; Li, W.; Movia, D.; Giordani, S.; Zhang, H.; Leblanc, R.M. Conjugated Quantum Dots Inhibit the Amyloid B (1-42) Fibrillation Process. Int. J. Alzheimers Dis. 2011, 2011, 502386. [CrossRef] [PubMed]

168. Del Mar Martinez-Senac, M.; Villalain, J.; Gomez-Fernandez, J.C. Structure of the Alzheimer B-Amyloid Peptide (25-35) and Its Interaction with Negatively Charged Phospholipid Vesicles. Eur. J. Biochem. 1999, 265, 744-753. [CrossRef]

169. Sabaté, R.; Gallardo, M.; Estelrich, J. Spontaneous Incorporation of B-Amyloid Peptide into Neutral Liposomes. Colloids Surface A 2005, 270-271, 13-17. [CrossRef]

170. Terakawa, M.S.; Yagi, H.; Adachi, M.; Lee, Y.H.; Goto, Y. Small Liposomes Accelerate the Fibrillation of Amyloid B(1-40). J. Biol. Chem. 2015, 290, 815-826. [CrossRef]

171. Shimanouchi, T.; Onishi, R.; Kitaura, N.; Umakoshi, H.; Kuboi, R. Copper-Mediated Growth of Amyloid Beta Fibrils in the Presence of Oxidized and Negatively Charged Liposomes. J. Biosci. Bioeng. 2011, 112, 611-615. [CrossRef]

172. Tanifum, E.A.; Dasgupta, I.; Srivastava, M.; Bhavane, R.C.; Sun, L.; Berridge, J.; Pourgarzham, H.; Kamath, R.; Espinosa, G.; Cook, S.C.; et al. Intravenous Delivery of Targeted Liposomes to Amyloid-Beta Pathology in App/Psen1 Transgenic Mice. PLoS ONE 2012, 7, e48515. [CrossRef]

173. Airoldi, C.; Mourtas, S.; Cardona, F.; Zona, C.; Sironi, E.; D’Orazio, G.; Markoutsa, E.; Nicotra, F.; Antimisiaris, S.G.; La Ferla, B. Nanoliposomes Presenting on Surface a Cis-Glycofused Benzopyran Compound Display Binding Affinity and Aggregation Inhibition Ability Towards Amyloid B1-42 Peptide. Eur. J. Med. Chem. 2014, 85, 43-50. [CrossRef]

174. Carlred, L.; Gunnarsson, A.; Sole-Domenech, S.; Johansson, B.; Vukojevic, V.; Terenius, L.; Codita, A.; Winblad, B.; Schalling, M.; Hook, F.; et al. Simultaneous Imaging of Amyloid-Beta and Lipids in Brain Tissue Using Antibody-Coupled Liposomes and Time-of-Flight Secondary Ion Mass Spectrometry. J. Am. Chem. Soc. 2014, 136, 9973-9981. [CrossRef]

175. Gobbi, M.; Re, F.; Canovi, M.; Beeg, M.; Gregori, M.; Sesana, S.; Sonnino, S.; Brogioli, D.; Musicanti, C.; Gasco, P.; et al. Lipid-Based

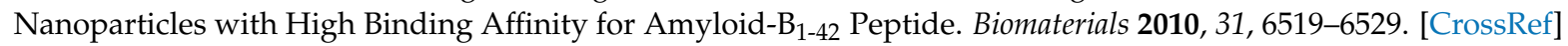

176. Bereczki, E.; Re, F.; Masserini, M.E.; Winblad, B.; Pei, J.J. Liposomes Functionalized with Acidic Lipids Rescue A $\beta$-Induced Toxicity in Murine Neuroblastoma Cells. Nanomedicine 2011, 7, 560-571. [CrossRef]

177. Mourtas, S.; Canovi, M.; Zona, C.; Aurilia, D.; Niarakis, A.; La Ferla, B.; Salmona, M.; Nicotra, F.; Gobbi, M.; Antimisiaris, S.G. Curcumin-Decorated Nanoliposomes with Very High Affinity for Amyloid-B1-42 Peptide. Biomaterials 2011, 32, 1635-1645. [CrossRef] [PubMed]

178. Taylor, M.; Moore, S.; Mourtas, S.; Niarakis, A.; Re, F.; Zona, C.; La Ferla, B.; Nicotra, F.; Masserini, M.; Antimisiaris, S.G.; et al. Effect of Curcumin-Associated and Lipid Ligand-Functionalized Nanoliposomes on Aggregation of the Alzheimer's A $\beta$ Peptide. Nanomedicine 2011, 7, 541-550. [CrossRef] [PubMed]

179. Canovi, M.; Markoutsa, E.; Lazar, A.N.; Pampalakis, G.; Clemente, C.; Re, F.; Sesana, S.; Masserini, M.; Salmona, M.; Duyckaerts, C.; et al. The Binding Affinity of Anti-A $\beta_{1-42}$ Mab-Decorated Nanoliposomes to A $\beta_{1-42}$ Peptides In Vitro and to Amyloid Deposits in Post-Mortem Tissue. Biomaterials 2011, 32, 5489-5497. [CrossRef] [PubMed] 
180. Re, F.; Cambianica, I.; Sesana, S.; Salvati, E.; Cagnotto, A.; Salmona, M.; Couraud, P.O.; Moghimi, S.M.; Masserini, M.; Sancini, G. Functionalization with Apoe-Derived Peptides Enhances the Interaction with Brain Capillary Endothelial Cells of Nanoliposomes Binding Amyloid-Beta Peptide. J. Biotechnol. 2011, 156, 341-346. [CrossRef]

181. Salvati, E.; Re, F.; Sesana, S.; Cambianica, I.; Sancini, G.; Masserini, M.; Gregori, M. Liposomes Functionalized to Overcome the Blood-Brain Barrier and to Target Amyloid-Beta Peptide: The Chemical Design Affects the Permeability across an In Vitro Model. Int. J. Nanomed. 2013, 8, 1749-1758. [CrossRef]

182. Mourtas, S.; Lazar, A.N.; Markoutsa, E.; Duyckaerts, C.; Antimisiaris, S.G. Multifunctional Nanoliposomes with Curcumin-Lipid Derivative and Brain Targeting Functionality with Potential Applications for Alzheimer Disease. Eur. J. Med. Chem. 2014, 80, 175-183. [CrossRef]

183. Bana, L.; Minniti, S.; Salvati, E.; Sesana, S.; Zambelli, V.; Cagnotto, A.; Orlando, A.; Cazzaniga, E.; Zwart, R.; Scheper, W.; et al. Liposomes Bi-Functionalized with Phosphatidic Acid and an Apoe-Derived Peptide Affect Abeta Aggregation Features and Cross the Blood-Brain-Barrier: Implications for Therapy of Alzheimer Disease. Nanomedicine 2014, 10, 1583-1590. [CrossRef]

184. Balducci, C.; Mancini, S.; Minniti, S.; La Vitola, P.; Zotti, M.; Sancini, G.; Mauri, M.; Cagnotto, A.; Colombo, L.; Fiordaliso, F.; et al. Multifunctional Liposomes Reduce Brain B-Amyloid Burden and Ameliorate Memory Impairment in Alzheimer's Disease Mouse Models. J. Neurosci. 2014, 34, 14022-14031. [CrossRef]

185. Cabaleiro-Lago, C.; Quinlan-Pluck, F.; Lynch, I.; Lindman, S.; Minogue, A.M.; Thulin, E.; Walsh, D.M.; Dawson, K.A.; Linse, S. Inhibition of Amyloid Beta Protein Fibrillation by Polymeric Nanoparticles. J. Am. Chem. Soc. 2008, 130, 15437-15443. [CrossRef]

186. Cabaleiro-Lago, C.; Quinlan-Pluck, F.; Lynch, I.; Dawson, K.A.; Linse, S. Dual Effect of Amino Modified Polystyrene Nanoparticles on Amyloid Beta Protein Fibrillation. ACS Chem. Neurosci. 2010, 1, 279-287. [CrossRef]

187. Jha, A.; Ghormade, V.; Kolge, H.; Paknikar, K.M. Dual Effect of Chitosan-Based Nanoparticles on the Inhibition of B-Amyloid Peptide Aggregation and Disintegration of the Preformed Fibrils. J. Mater. Chem. B 2019, 7, 3362-3373. [CrossRef]

188. Ye, Z.; Wei, L.; Li, Y.; Xiao, L. Efficient Modulation of B-Amyloid Peptide Fibrillation with Polymer Nanoparticles Revealed by Super-Resolution Optical Microscopy. Anal. Chem. 2019, 91, 8582-8590. [CrossRef]

189. Xu, Y.; Xiao, L. Efficient Suppression of Amyloid-Beta Peptide Aggregation and Cytotoxicity with Photosensitive Polymer Nanodots. J. Mater. Chem. B 2020, 8, 5776-5782. [CrossRef]

190. Dou, W.T.; Lv, Y.; Tan, C.; Chen, G.R.; He, X.P. Irreversible Destruction of Amyloid Fibril Plaques by Conjugated Polymer Based Fluorogenic Nanogrenades. J. Mater. Chem. B 2016, 4, 4502-4506. [CrossRef]

191. Lai, Y.; Zhu, Y.; Xu, Z.; Hu, X.; Saeed, M.; Yu, H.; Chen, X.; Liu, J.; Zhang, W. Engineering Versatile Nanoparticles for near-Infrared Light-Tunable Drug Release and Photothermal Degradation of Amyloid B. Adv. Funct. Mater. 2020, 30, 1908473. [CrossRef]

192. Liu, L.; Chang, Y.; Yu, J.; Jiang, M.; Xia, N. Two-in-One Polydopamine Nanospheres for Fluorescent Determination of BetaAmyloid Oligomers and Inhibition of Beta-Amyloid Aggregation. Sensor. Actuat. B-Chem. 2017, 251, 359-365. [CrossRef]

193. Liu, Z.; Ma, M.; Yu, D.; Ren, J.; Qu, X. Target-Driven Supramolecular Self-Assembly for Selective Amyloid-B Photooxygenation against Alzheimer's Disease. Chem. Sci. 2020, 11, 11003-11008. [CrossRef]

194. Kuk, S.; Lee, B.I.; Lee, J.S.; Park, C.B. Rattle-Structured Upconversion Nanoparticles for near-Ir-Induced Suppression of Alzheimer's B-Amyloid Aggregation. Small 2017, 13, 1603139. [CrossRef]

195. Ma, M.; Gao, N.; Sun, Y.; Ren, J.; Qu, X. A near-Infrared Responsive Drug Sequential Release System for Better Eradicating Amyloid Aggregates. Small 2017, 13, 1701817. [CrossRef]

196. Zhang, H.; Hao, C.; Qu, A.; Sun, M.; Xu, L.; Xu, C.; Kuang, H. Light-Induced Chiral Iron Copper Selenide Nanoparticles Prevent B-Amyloidopathy in Vivo. Angew. Chem. Int. Ed. Engl. 2020, 59, 7131-7138. [CrossRef]

197. Sun, J.; Xie, W.; Zhu, X.; Xu, M.; Liu, J. Sulfur Nanoparticles with Novel Morphologies Coupled with Brain-Targeting Peptides Rvg as a New Type of Inhibitor against Metal-Induced A $\beta$ Aggregation. ACS Chem. Neurosci. 2018, 9, 749-761. [CrossRef]

198. Huang, K.; Li, Z.; Lin, J.; Han, G.; Huang, P. Two-Dimensional Transition Metal Carbides and Nitrides (Mxenes) for Biomedical Applications. Chem. Soc. Rev. 2018, 47, 5109-5124. [CrossRef] 